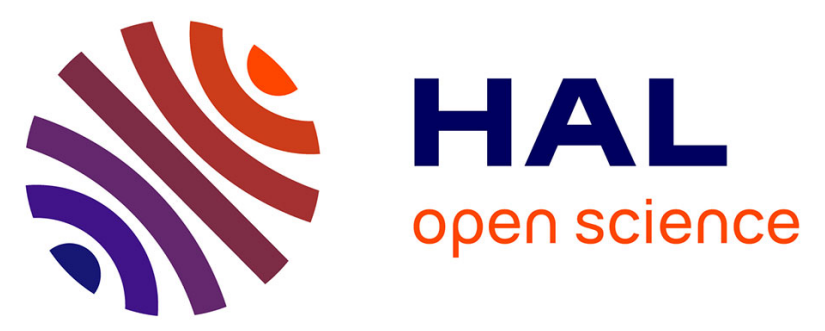

\title{
Electrical properties of iron corrosion layers formed in anoxic environments at the nanometer scale
}

Florence F. Mercier-Bion, Jiaying Li, Hélène Lotz, Ludovic Tortech, Delphine D. Neff, Philippe Dillmann

\section{- To cite this version:}

Florence F. Mercier-Bion, Jiaying Li, Hélène Lotz, Ludovic Tortech, Delphine D. Neff, et al.. Electrical properties of iron corrosion layers formed in anoxic environments at the nanometer scale. Corrosion Science, In press, 137, pp.98-110. 10.1016/j.corsci.2018.03.028 . cea-01743218

\section{HAL Id: cea-01743218 https://hal-cea.archives-ouvertes.fr/cea-01743218}

Submitted on 27 Mar 2018

HAL is a multi-disciplinary open access archive for the deposit and dissemination of scientific research documents, whether they are published or not. The documents may come from teaching and research institutions in France or abroad, or from public or private research centers.
L'archive ouverte pluridisciplinaire HAL, est destinée au dépôt et à la diffusion de documents scientifiques de niveau recherche, publiés ou non, émanant des établissements d'enseignement et de recherche français ou étrangers, des laboratoires publics ou privés. 


\title{
Electrical properties of iron corrosion layers formed in anoxic environments at the nanometer scale
}

\author{
Florence MERCIER-BION*(1), Jiaying LI ${ }^{(1)}$, Hélène $\operatorname{LOTZ}^{(1)}$, Ludovic TORTECH ${ }^{(2,3)}$, \\ Delphine $\operatorname{NEFF}^{(1)}$, Philippe DILLMANN ${ }^{(1)}$
}

(1) LAPA-IRAMAT, NIMBE, CEA, CNRS, Université Paris-Saclay, CEA Saclay 91191 Gif-surYvette, France

(2) Sorbonne Universités, UPMC Université Paris 06, UMR 8232, Institut Parisien de Chimie Moléculaire (IPCM), 75005 Paris, France

(3) CEA Saclay, IRAMIS, NIMBE (UMR 3685), Laboratoire d'Innovation en Chimie des Surfaces et Nanosciences (LICSEN), 91191 Gif-sur-Yvette, France

*Corresponding author's e-mail address: florence.mercier@cea.fr (F. Mercier-Bion).

\section{Abstract}

The electrical properties of the corrosion layers on archaeological iron artefacts were determined by Conductive Atomic Force Microscopy. Different corrosion products were studied: Fe" carbonates, magnetite entrapped in the carbonate, and iron sulfides. The results indicate that the ferrous carbonate matrix is insulating, and that magnetite and iron sulfides have a conductive character, although these phases are not systematically connected to the metal. This suggests that electrons produced by the anodic dissolution of metal would be conducted to the external part of the corrosion product layer through a three-dimensional network of connected magnetite strips passing through the ferrous carbonate matrix.

Keywords: C-AFM; Iron corrosion; Electrical properties, Archaeological artefact, $\mu$ Raman, FESEM.

\section{Introduction}

In addition to studies concerning short-term corrosion processes (for example, steel pipeline behaviour [1]), long-term iron corrosion in carbonated anoxic media has also been 
widely studied in recent years with two main objectives. The first, aims to predict the corrosion of low alloy steel overcontainers for nuclear waste disposal [2-12]; the second, concerns the domain of in situ preservation of archaeological remains buried in anoxic carbonated soils $[13,14]$.

The iron corrosion anodic reaction involves the oxidative dissolution of metal into ferrous ions. In anoxic water-saturated environments, the corrosion cathodic reaction involving water reduction, or the reduction of $\mathrm{H}_{2} \mathrm{CO}_{3}$ or $\mathrm{HCO}_{3}{ }^{-}$according to the $\mathrm{pH}$, can also occur.

For all systems involving the corrosion of iron in carbonated anoxic medium, the corrosion product layers show similar trends regarding the nature of the corrosion products: primarily $\mathrm{Fe}^{\prime \prime}$ carbonates, either siderite $\mathrm{Fe}^{\prime \prime} \mathrm{CO}_{3}$ or a mix of siderite and chukanovite $\mathrm{Fe}_{2}{ }_{2}(\mathrm{OH})_{2} \mathrm{CO}_{3}$, with the occasional presence of iron oxides such as magnetite $\mathrm{Fe}^{\mathrm{II}, \mathrm{II}}{ }_{3} \mathrm{O}_{4}$. This is true for both century-long corrosion periods, as with iron archaeological artefacts corroded over hundreds or thousands of years [7-9], or for iron coupons corroded in laboratory experiments for just months, or years, under pressure and temperature controlled conditions $[4,10-12,15]$. The presence of iron sulfides was also sometimes reported inside the corrosion product layer (CPL) of iron artefacts corroded in natural carbonated anoxic medium. This is probably linked to the presence of sulfate-reducing bacteria in deep anoxic media. Fell et al. [16] showed, from transverse sections of several iron objects extracted from waterlogged soil at the Iron Age Fiskerton site (Lincolnshire, UK), that iron sulfides were contained in the outer part of the CPL. More recently, Grousset et al. [9] have described the iron sulfides in the CPL of iron artefacts coming from different anoxic sites (terrestrial or subaquatic). A diversity of iron sulfides was observed in the outer border of the corrosion product layer: mackinawite $\mathrm{FeS}_{1-x}$, greigite $\left(\mathrm{Fe}_{3} \mathrm{~S}_{4}\right)$ and pyrite $\left(\mathrm{FeS}_{2}\right)$. The 
formation of iron sulfides may be attributed to the presence of sulfate-reducing bacteria in the burial environment.

Moreover, in the systems collected from the Glinet archaeological site (Seine Maritime, France), widely studied for its anoxic environment $[4,6,7,17]$, in most cases, magnetite is not directly connected to the iron metal. However, it is present underneath small strips and nodules in the ferrous carbonate layer matrix constituting the CPL or underneath thick strips (up to $200 \mu \mathrm{m}$ ) in the outer part of the CPL. This presence of magnetite connected to the metal, enables the decoupling of anodic and cathodic corrosion reactions and subsequently influences the corrosion behaviour (see below) and the way to model it.

Several authors $[11,18,19]$ have focused their studies on the anodic reaction that is always located at the metal/CPL interface. Corrosion studies involving the cathodic reaction are less common. On the archaeological iron artefacts from the Glinet site, Saheb et al. [7] (2011b) have highlighted, with reaction tracing based on the use of the $\mathrm{Cu}^{2+} / \mathrm{Cu}^{0}$ redox couple, the presence of $\mathrm{Cu}^{0}$ everywhere in the thick corrosion layer $(200 \mu \mathrm{m})$. This observation suggests the consumption of electrons everywhere in the corrosion layer and the decoupling of anodic and cathodic reactions. In several studies [14, 20], siderite is considered isolating, although it is difficult to measure resistivity values, especially on siderite formed due to iron corrosion. Magnetite is a semi-conductor that presents a low resistivity of $5.62 \times 10^{3} \Omega . \mathrm{cm}$ [21] due to the possible electronic transfer between $\mathrm{Fe}^{\text {II }}$ and $\mathrm{Fe}$ III in its structure [22]. Thus, the electronic conduction in the layer could be caused by the presence of this phase. Nevertheless, in most cases, this phase is present in the system in the form of islets embedded in the carbonate matrix and does not seem to be electrically connected to the metallic substrate. Lastly, another hypothesis to explain the electronic 
transfer is the presence of a non-detected nanometre network of conductive phases (probably magnetite), allowing the decoupling of anodic and cathodic reactions.

Considering all of these aspects, we wanted to gain a better understanding of the potential location of the corrosion cathodic reaction by investigating the electronic properties of the corrosion layers developed on artefacts from the Glinet site. For this purpose, we used Conductive Atomic Force Microscopy (C-AFM), which is unique in its capability to probe electrical characteristics with nanometre-scale resolution. Beforehand, $\mu$ Raman spectroscopy was performed for the identification of the crystalline nature of the corrosion products.

Different corrosion profiles of the CPL were investigated: CPL constituted only by ferrous carbonate, $\mathrm{CPL}$ of carbonates with the presence of magnetite in different morphologies, and CPL of carbonates with the presence of iron sulfide phases, were also detected in the examined samples. As for magnetite, the presence of these conductive phases in the CPL could drastically change the corrosion behaviour of the system. That is why sulfides are also considered in this study.

\section{Materials and Methods}

\subsection{Samples}

Two 500-year-old nails (GL12-72: 3 zones, GL07-35: 1 zone) from the Glinet archaeological site (Seine-Maritime, France) were studied. After their excavation from the anoxic carbonated site, the nails are preserved in ethanol (Ultrapur). All preparation steps were carried out in an $\mathrm{N}_{2}$ glove-box: drying, epoxy-resin embedding, cutting and surface polishing with SiC papers (180-4000) and diamond spray $(1 \mu \mathrm{m})$ under ethanol. The polished 
transverse sections of these nails were analysed by the different techniques: $\mu$ Raman spectroscopy, Field-Emission Scanning Electron Microscopy (FESEM) and C-AFM.

\subsection{Analytical techniques}

$\mu$ Raman Spectroscopy $(\mu R S)$

$\mu \mathrm{RS}$ measurements were carried out via an Invia Reflex ${ }^{\circledR}$ spectrometer with an excitation wavelength of $532 \mathrm{~nm}$. The laser power was filtered down to $0.1 \mathrm{~mW}$ and the spectra were recorded with an X50 objective delivering a beam size of $1 \mu \mathrm{m}$ with a probe depth of about $1 \mu \mathrm{m}$. The spectral resolution was $2 \mathrm{~cm}^{-1}$. The spectrometer calibration was obtained from a silicon wafer $\left(520.5 \mathrm{~cm}^{-1}\right)$. Acquisition and treatment of the spectra were performed with Wire $3.4^{\circledR}$ software. All the spectra are presented without smoothing or line fitting in our study.

$\mu$ Raman maps were acquired in point-to-point mode with a step size of $1 \mu \mathrm{m}$ and the acquisition time for each point of the map was 120 seconds. To obtain the distribution of each corrosion product in the mapped zone, the map was treated by the Direct Classical Least Square analysis method available in the Wire ${ }^{\oplus}$ software. Each spectrum obtained on a single pixel of the map is decomposed by the reference spectra of the phases present in the sample. The reference Raman spectra of the iron corrosion products characteristic of a carbonated anoxic environment (Figure 1) were obtained from magnetite $\left(\mathrm{Fe}_{3} \mathrm{O}_{4}\right)$ powders, and from phases present in the corrosion product layers of ferrous archaeological nails collected from anoxic and carbonated medium when reference powders were missing: siderite $\left(\mathrm{FeCO}_{3}\right)$ and chukanovite $\left(\mathrm{Fe}(\mathrm{OH})_{2} \mathrm{CO}_{3}\right)$.

The phases (siderite, chukanovite and magnetite) were also analysed by XRD and do not show other additional phases. In SEM Energy Dispersive Spectrometry (EDS) analyses, no 
element other than $\mathrm{C}, \mathrm{O}$, and Fe was detected. For these reasons, these phases were considered as references for our studies on the determination of the nature of the corrosion products.

a)

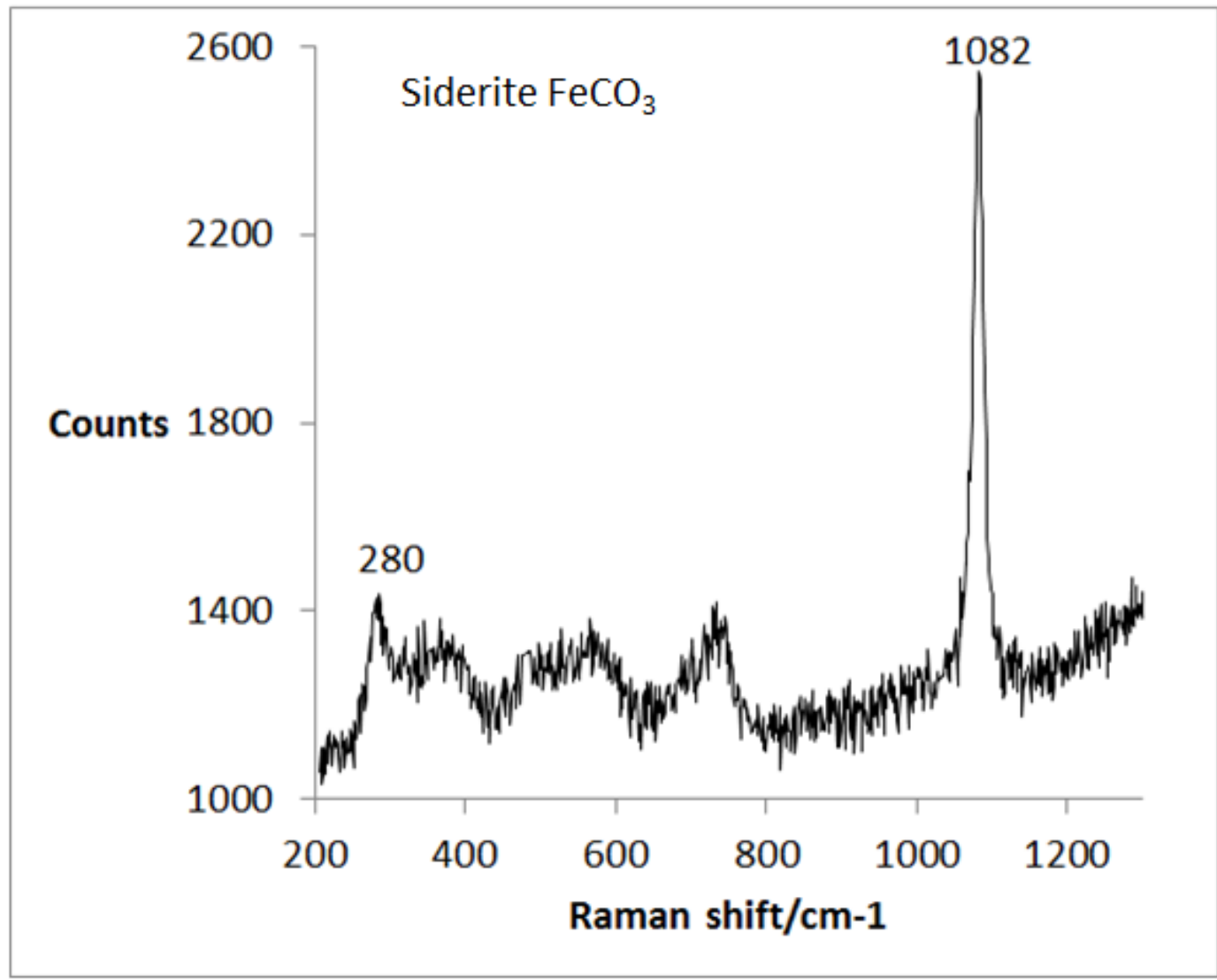


b)

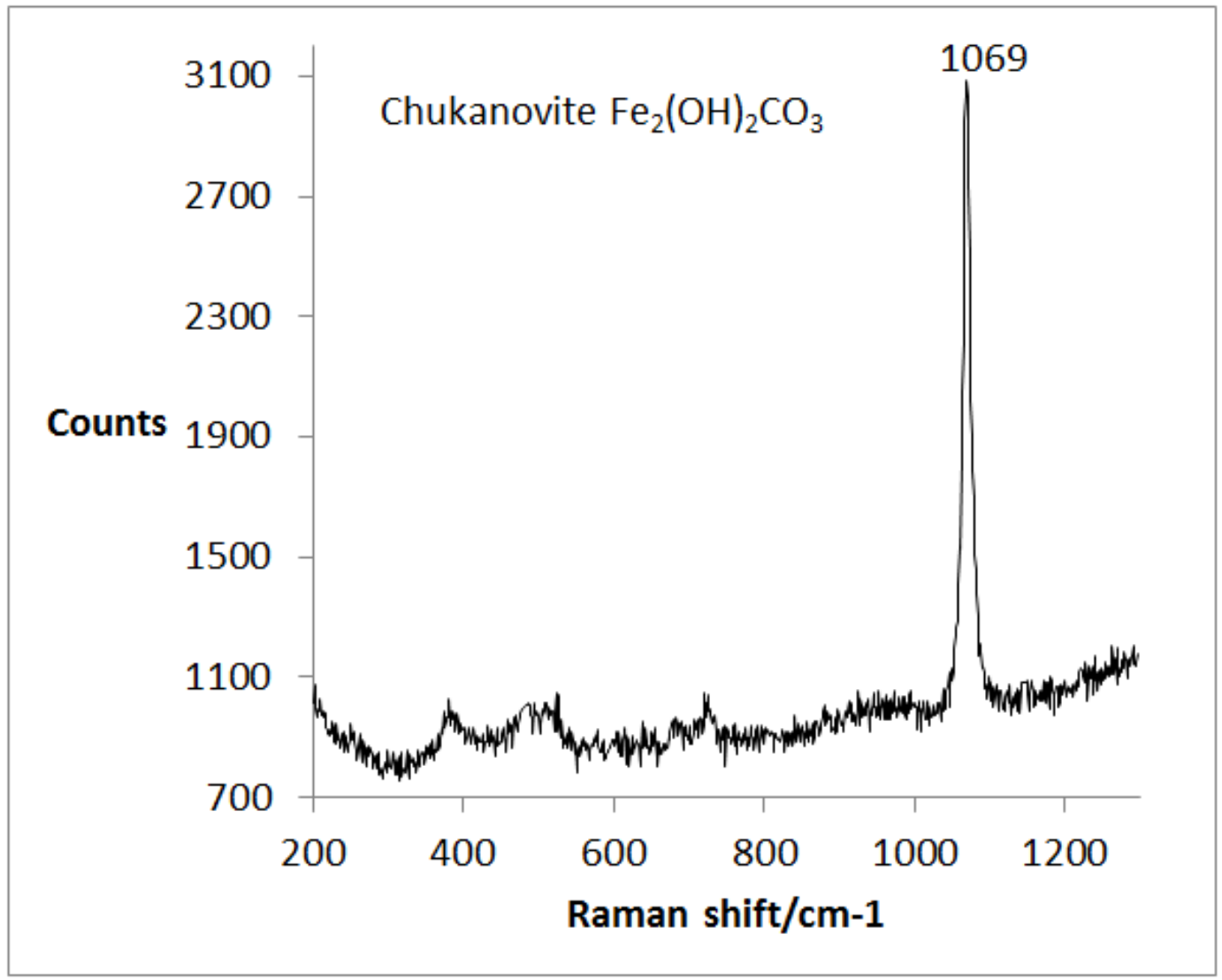


c)

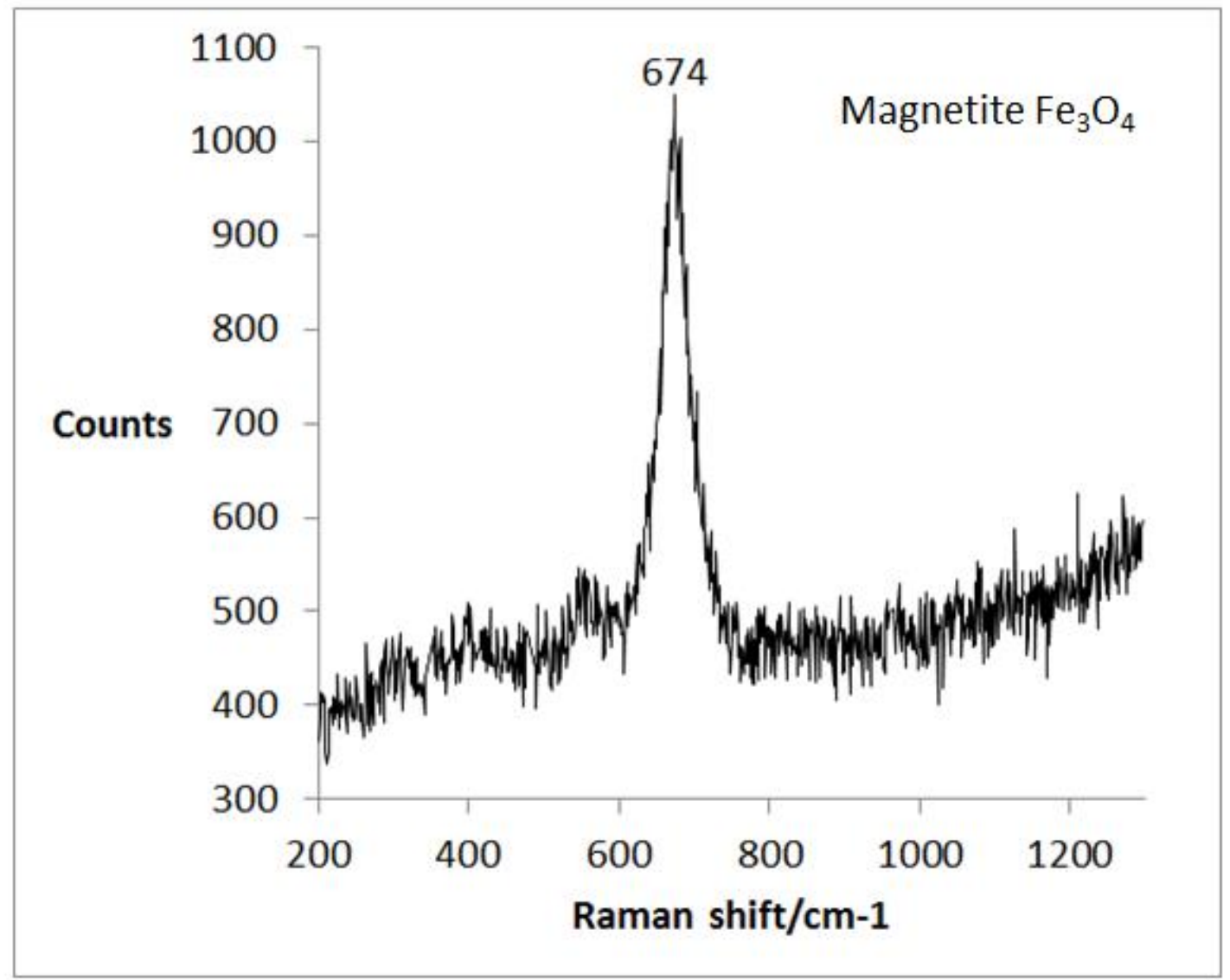

Figure 1 - Reference Raman spectra of the iron corrosion products characteristic of a carbonated anoxic environment: siderite $\mathrm{FeCO}_{3}(\mathrm{a})$; chukanovite $\mathrm{Fe}(\mathrm{OH})_{2} \mathrm{CO}_{3}(\mathrm{~b})$; magnetite $\mathrm{Fe}_{3} \mathrm{O}_{4}(\mathrm{c})$.

\section{Field Emission Scanning Electron Microscopy}

On the samples prepared as transverse sections (as for $\mu$ Raman experiments), Backscattered Electron (BSE) images and elemental maps of the corrosion layers from coremetal to outer soil by EDS were obtained on a FESEM JEOL JSM-7001F. An incident acceleration voltage of $10 \mathrm{kV}$ and a beam current of $12 \mathrm{nA}$ were used. A carbon-coating layer of $15 \mathrm{~nm}$ was deposited on the sample surface before FESEM analysis. 


\section{Conductive Atomic Force Microscopy}

Conductive Atomic Force Microscopy (C-AFM) measurements were performed on a Bruker FastScan/Icon Atomic Force microscope. The conductive mode was selected and the calibre was chosen for high resolution and low current at $1 \mathrm{nA} / \mathrm{V}$ and below to optimize the current contrast. Two types of tips were used: either with high cantilever's spring constant (K $>20 \mathrm{n} / \mathrm{m}$ ) and diamond coating to measure the metal/oxide interface or with low spring constant $(1 \mathrm{~N} / \mathrm{m}<\mathrm{K})$ and Pt/Ir coating. Regardless of the tip used, it was in contact mode and the contact area tip-CPL was estimated in the range of $80 \mathrm{~nm}^{2}$ to $180 \mathrm{~nm}^{2}$. The measurements were performed by applying a constant voltage between the tip and the metal electrode. Bias voltage was applied to the nail. For each area scanned by the tip, the topography and the current images were collected simultaneously.

Conductive Atomic Force Microscopy was used to map the transverse section of the corrosion product layer at the nanometre-scale. The conductive character of the different phases constituting the corrosion product layers and the identification of the electron conduction channels inside these layers were determined.

Two strategies were used to discriminate the electrical pathways in the corrosion product layers: (1) biased the front side of the transverse section of the sample (Figure 2a-c) and (2) biased of the backside of the sample (Figure $2 b-d$ ). In model 1 , the electrons extracted from the closed circuit necessarily transit through the metallic body of the nail. As a consequence, the transverse electrical pathway " $\mathrm{CPL}$ - metallic core" will be highlighted. In model 2, backside contact, the measured current could come either from a pure CPL bulk conduction or a shortcut to the metallic nail core (model 1). 
a) Front Contact

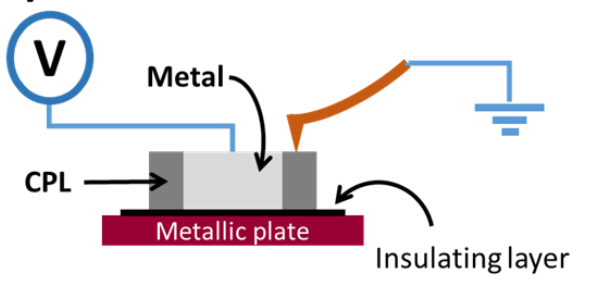

c)

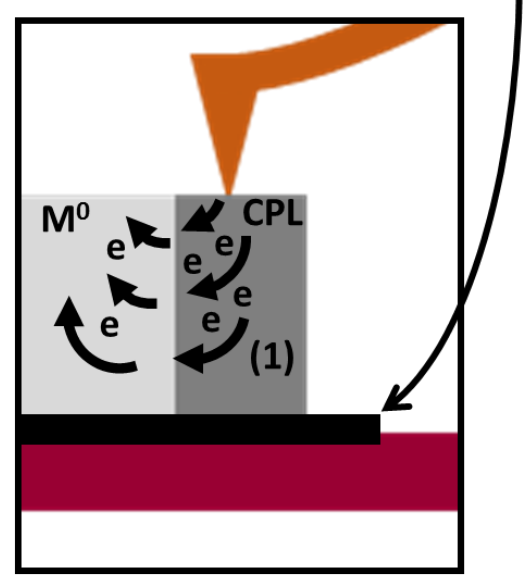

(1) Exclusive metallic core conduction b) Back Contact

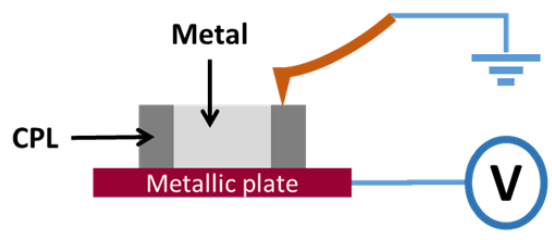

d)

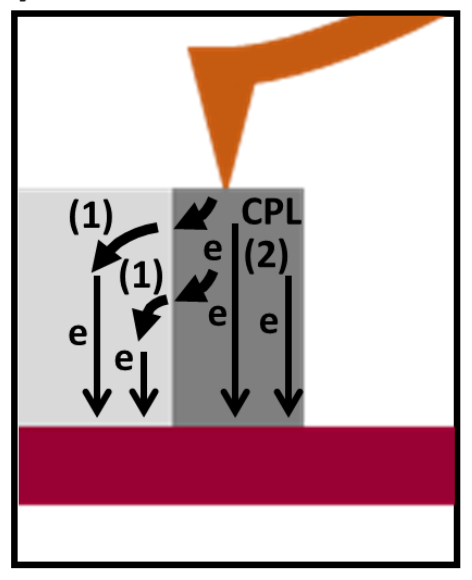

(1) metallic core conduction

(2) CPL Bulk conduction

Figure 2 - schematic representation of the electrical pathway with two models; $2 \mathrm{a}$ and $2 \mathrm{c}$ represent the front side contact, highlighting the presence of transverse electrical pathways in the CPL and $2 \mathrm{~b}$ and $2 \mathrm{~d}$ represent the backside contact for which the pure CP bulk conduction is possible, as well as the lateral conduction.

\section{Results}

Different corrosion patterns in the CPLs were characterized for the two archaeological nails (GL12-72: 3 zones, GL07-35: 1 zone) in terms of both the nature and distribution of the corrosion products and the electronic properties.

As reported in the literature [5], the corrosion layers from core-metal to outer soil on iron archaeological artefacts buried in anoxic soils consist of the following zones:

-an iron metal core when the artefact is not entirely corroded;

-a corrosion layer called dense product layer or CPL that is in contact with the metal and is in most cases denser than the burial environment; this layer is made of mainly ferrous 
carbonates (siderite, chukanovite), as well as magnetite. The corrosion patterns for archaeological iron objects corroded in carbonated anoxic medium mainly differ in the relative localization of these phases in the $\mathrm{CPL}$;

-a more porous layer called transformed medium (TM) that presents soil compounds (quartz, calcite, clays,...) mixed with iron corrosion products, and the soil itself.

These different layers are presented on the schematic representation in Figure 3.

In some areas of the CPLs, the corrosion pattern indicates only ferrous carbonate matrix and thus the electronic properties of $\mathrm{Fe}^{\prime \prime}$ carbonates constituting the CPL were investigated. Other corrosion patterns were evident: the presence of magnetite in strips at the CPL/TM interface, the presence of magnetite in islets in the CPL, and the presence of iron sulfides in the CPL (Figure 3).

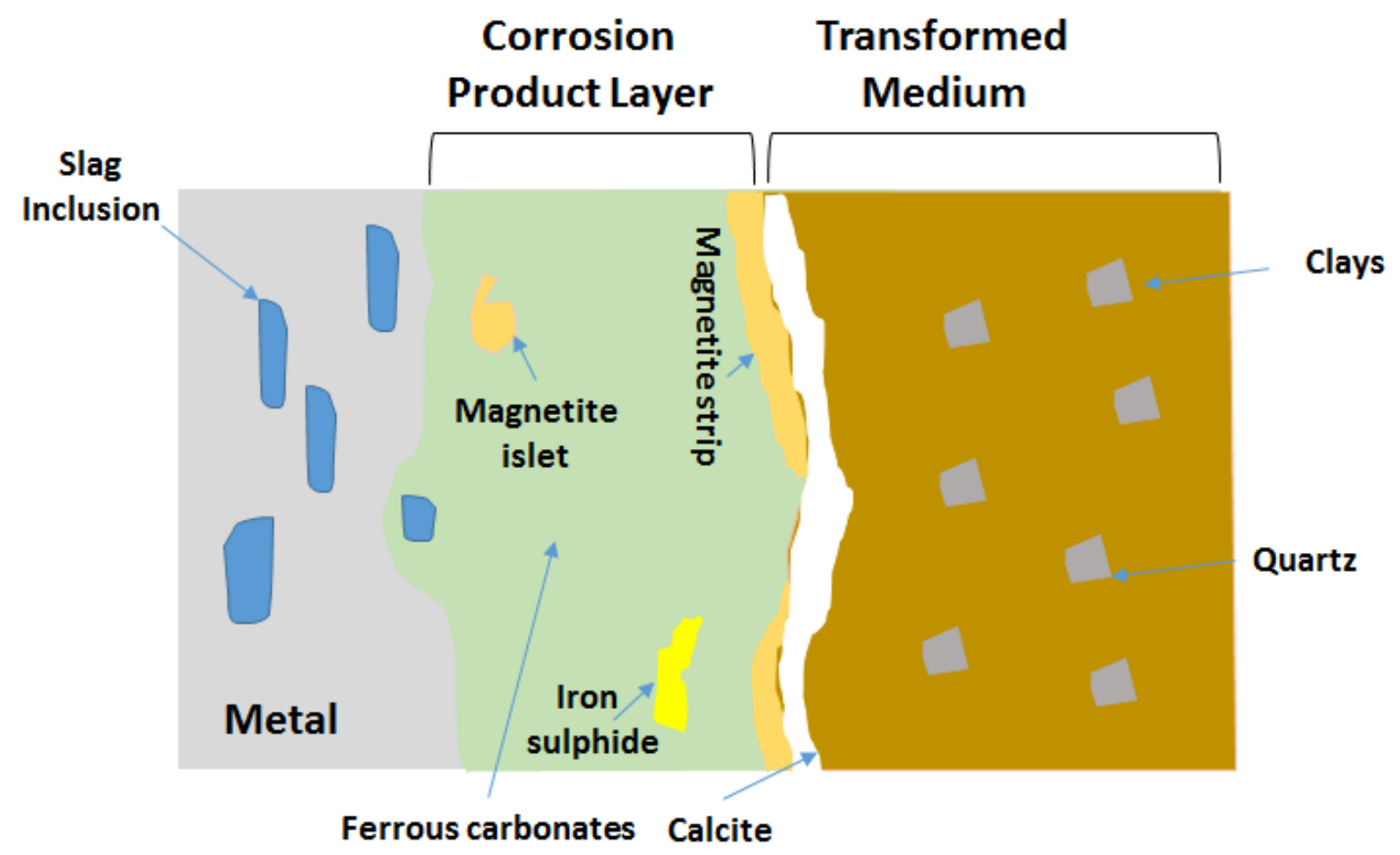

Figure 3 - Schematic view of the corrosion pattern observed on the archaeological iron nails from Glinet

These different corrosion patterns are demonstrated by using SEM EDS. 
An example of the corrosion pattern where the magnetite strips (arrow on the figure) are located at the CPL/TM interface is given in Figure 4. This figure displays a BSE image and SEM EDS maps of elements (O, Fe, $\mathrm{Al}, \mathrm{Si}, \mathrm{Ca}, \mathrm{K}, \mathrm{Na}, \mathrm{S})$ of the layers from core-metal to outer soil.

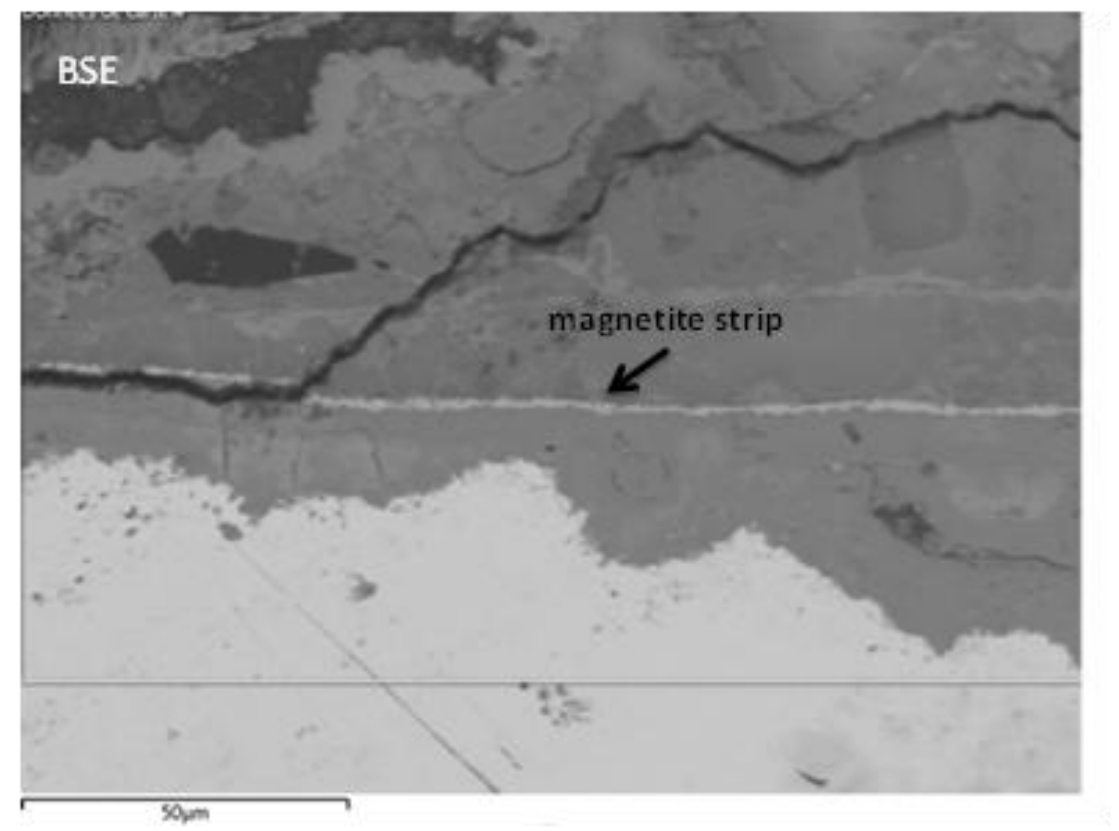



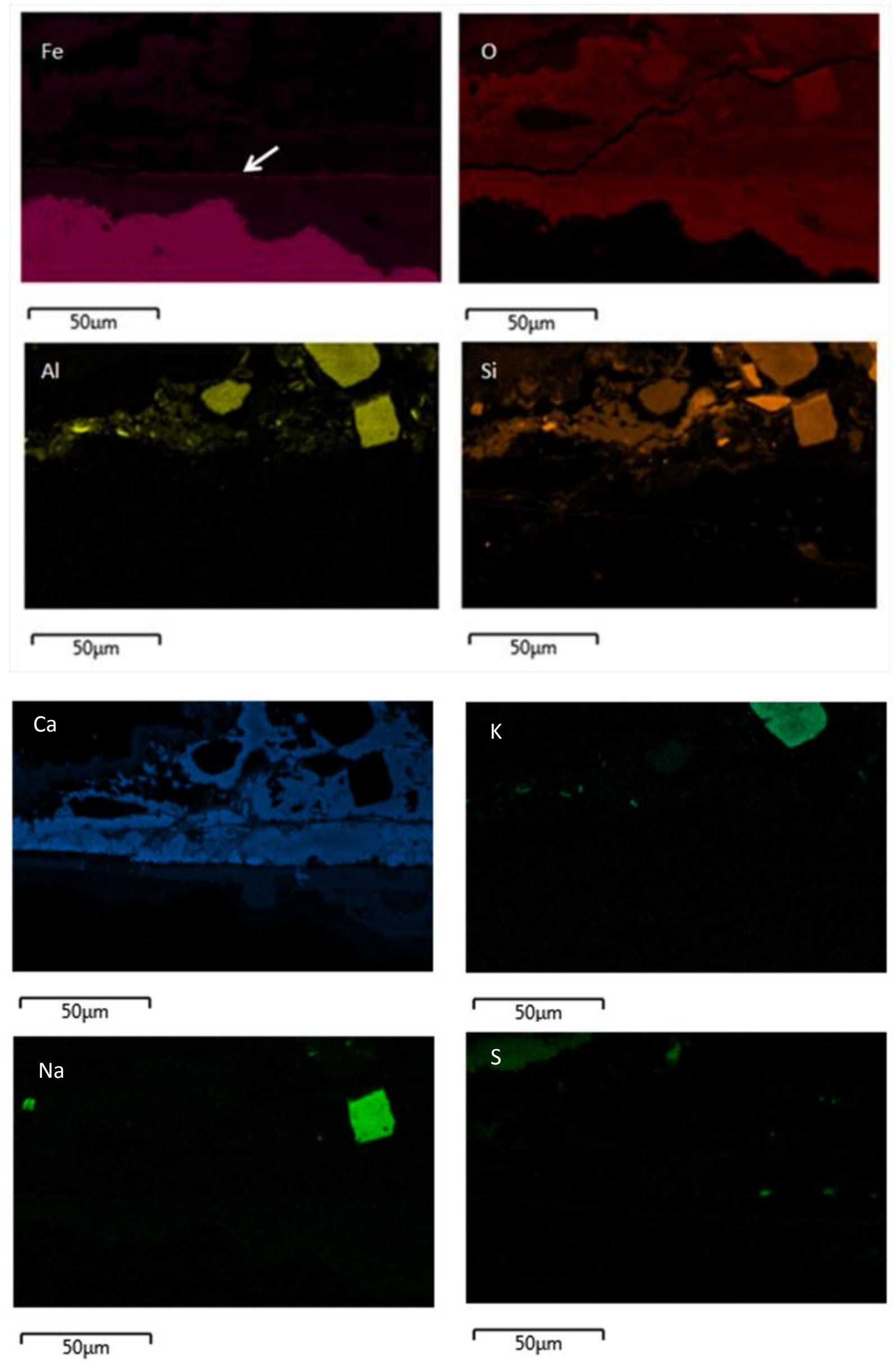
Figure 4 - BSE image and SEM EDS maps of elements (O, $\mathrm{Fe}, \mathrm{Al}, \mathrm{Si}, \mathrm{Ca}, \mathrm{K}, \mathrm{Na}, \mathrm{S})$ of the corrosion layer from iron metal to soil.

Some observations can be made regarding Figure 4 . On the elemental maps, the TM is clearly indicated by the presence of $\mathrm{Na}, \mathrm{Al}, \mathrm{Si}, \mathrm{K}$, and $\mathrm{Ca}$ that come from calcite, quartz, silica, and clays. It is also evident from elemental maps and the BSE image that the TM is more porous than the CPL. A magnetite strip, clearly seen on the BSE image and by Fe enrichment on the EDS map of this element (arrows on the BSE image and on the Fe map), is located at the CPL/TM interface, as is the case in some patterns of corrosion layers of iron archaeological nails buried in anoxic environments. Sulfur is present in the external part of the CPL and in the TM, which supports the findings of Grousset et al. [9] who found a diversity of iron sulfides at the outer border of the corrosion product layer: mackinawite $\mathrm{FeS}_{1-\mathrm{x}}$, greigite $\left(\mathrm{Fe}_{3} \mathrm{~S}_{4}\right)$ and pyrite $\left(\mathrm{FeS}_{2}\right)$.

An example of the corrosion pattern where the magnetite islets are in the CPL is given in Figure 5. This figure displays a BSE image and SEM EDS maps of Fe and O in the CPL.

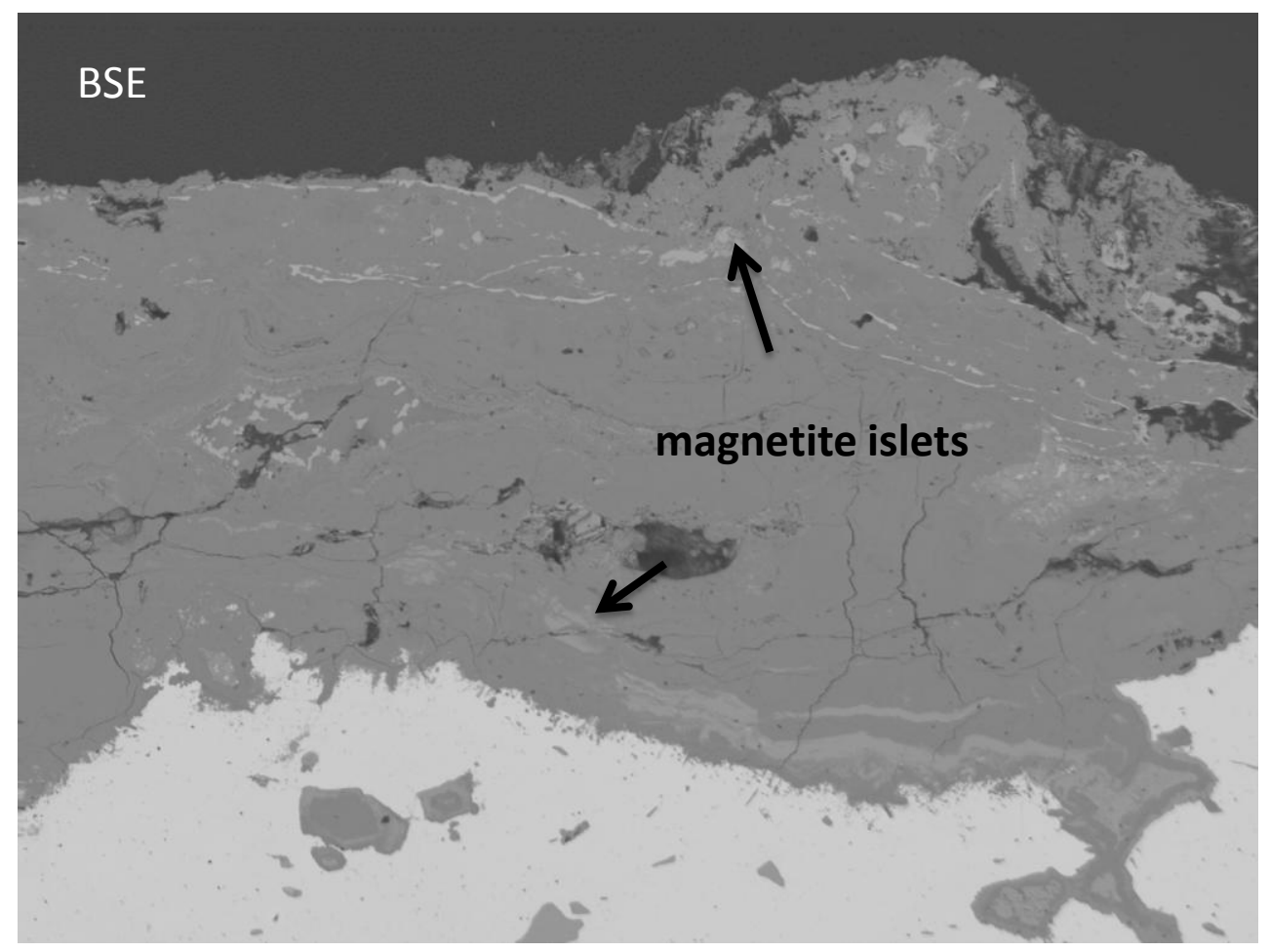




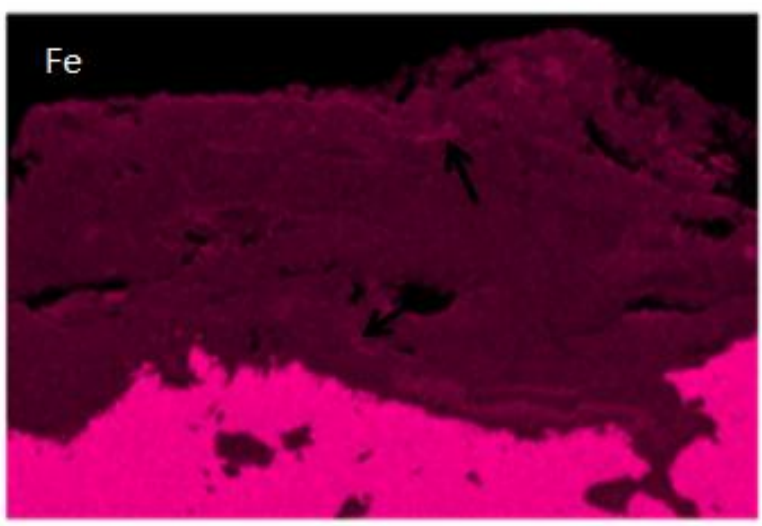

$250 \mu \mathrm{m}$

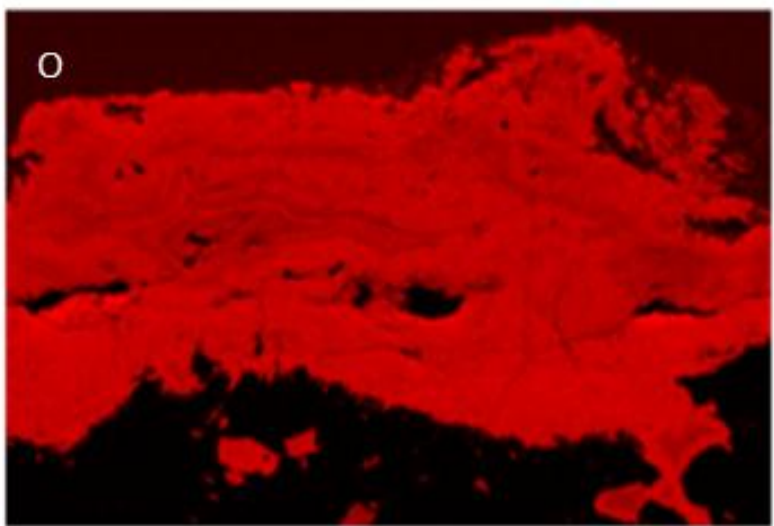

$250 \mu \mathrm{m}$

Figure 5 - BSE image and SEM EDS maps of Fe and O in the CPL.

In the BSE image, magnetite islets are clearly noted (see arrows on the image). They appear brighter than the carbonate matrix because of their higher mean atomic number. These magnetite islets are also evident on the Fe map by Fe enrichment (see arrows on the map).

Each of these corrosion patterns was investigated separately in terms of electrical properties determined by C-AFM experiments.

\subsection{Corrosion profiles containing only Fe" carbonates:}

An optical image obtained of the transverse section of the archaeological nail GL07-35 (Figure 6) shows different layers from the metal to the external part. As observed by studies related to the characterization of the corrosion forms on various archaeological iron artefacts buried in the carbonated anoxic sites of Nydam Mose and Glinet [3, 5-7], this transverse section consists of: an iron metallic core where the artefact is not entirely corroded; a corrosion layer called CPL in contact with the metal that is denser than the burial environment; a more porous layer that is TM containing soil compounds (quartz, silica, calcite, clays...) mixed with iron corrosion products and the soil in the external part. 


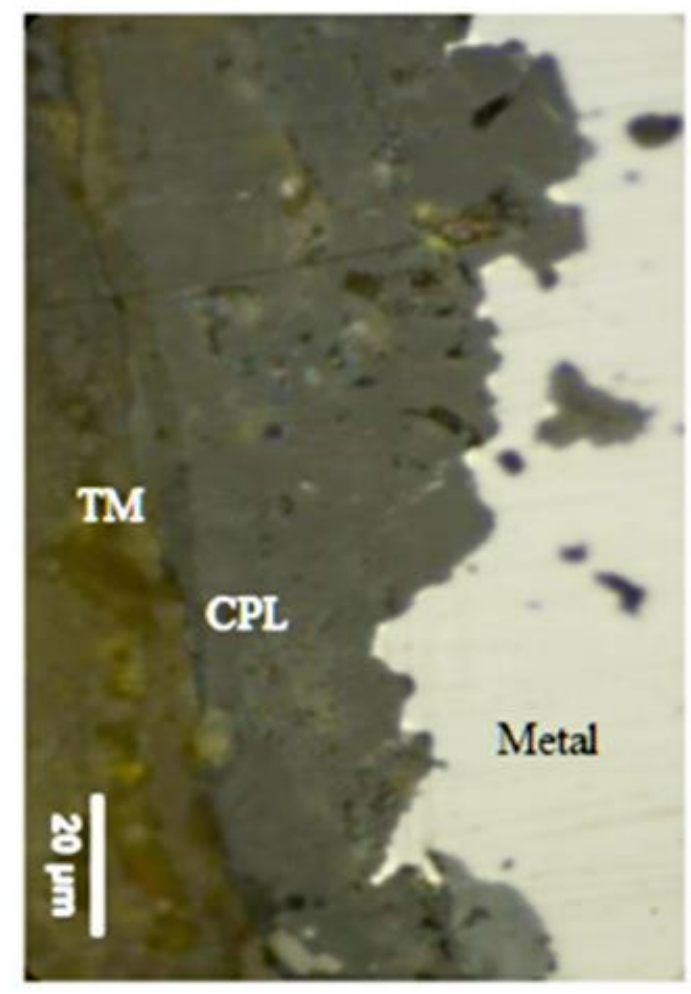

Figure 6 - Archaeological nail GL07-35: optical micrograph of the transverse section.

On the $\mu$ RS maps (Figure 7) corresponding to the optical micrograph of Figure 6, the only presence of $\mathrm{Fe}^{\text {II }}$ carbonates is highlighted: siderite $\mathrm{FeCO}_{3}$ through its main Raman peak at $1084 \mathrm{~cm}^{-1}$ and chukanovite $\mathrm{Fe}_{2}(\mathrm{OH})_{2} \mathrm{CO}_{3}$ with its main Raman peak at $1068 \mathrm{~cm}^{-1}$ [7]. Calcite, $\mathrm{CaCO}_{3}$, revealed by its very narrow and sharp peak at $1086 \mathrm{~cm}^{-1}$ and its high fluorescence yield, is present only in the TM. The other Raman peaks of each spectrum correspond to the minor bands of the phases. 

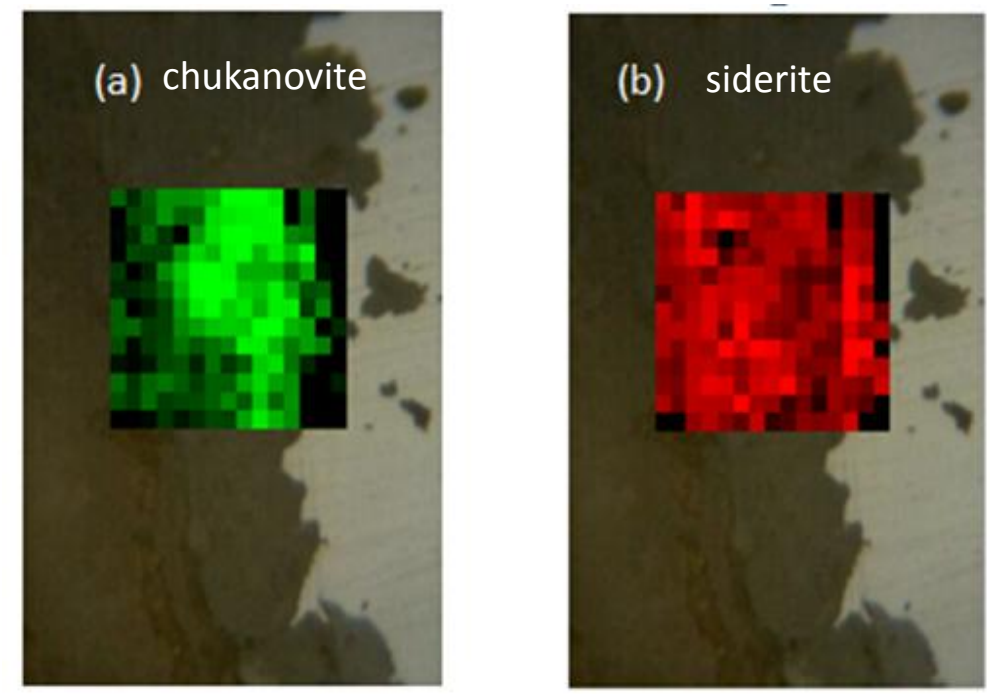

(c) calcite

d)

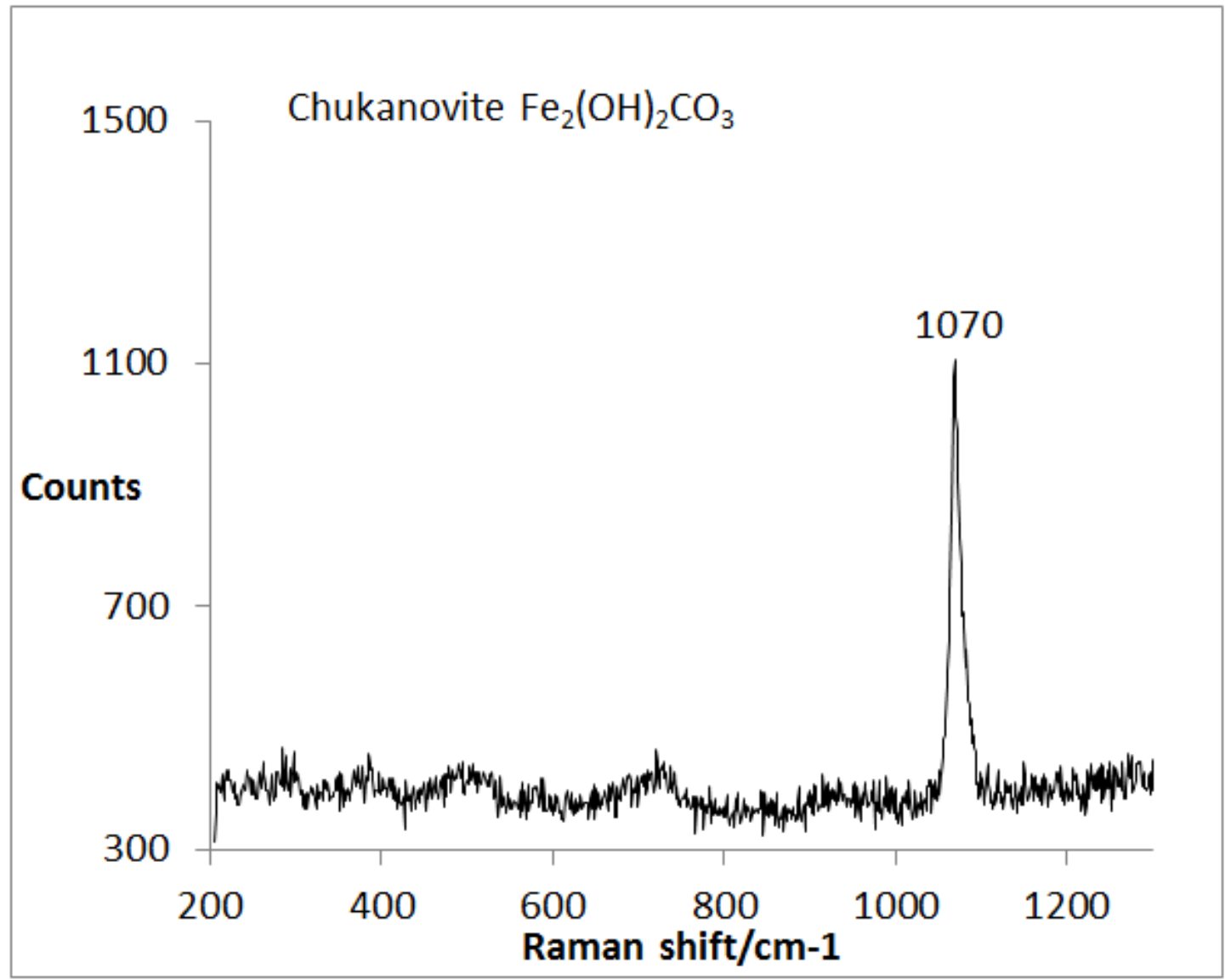




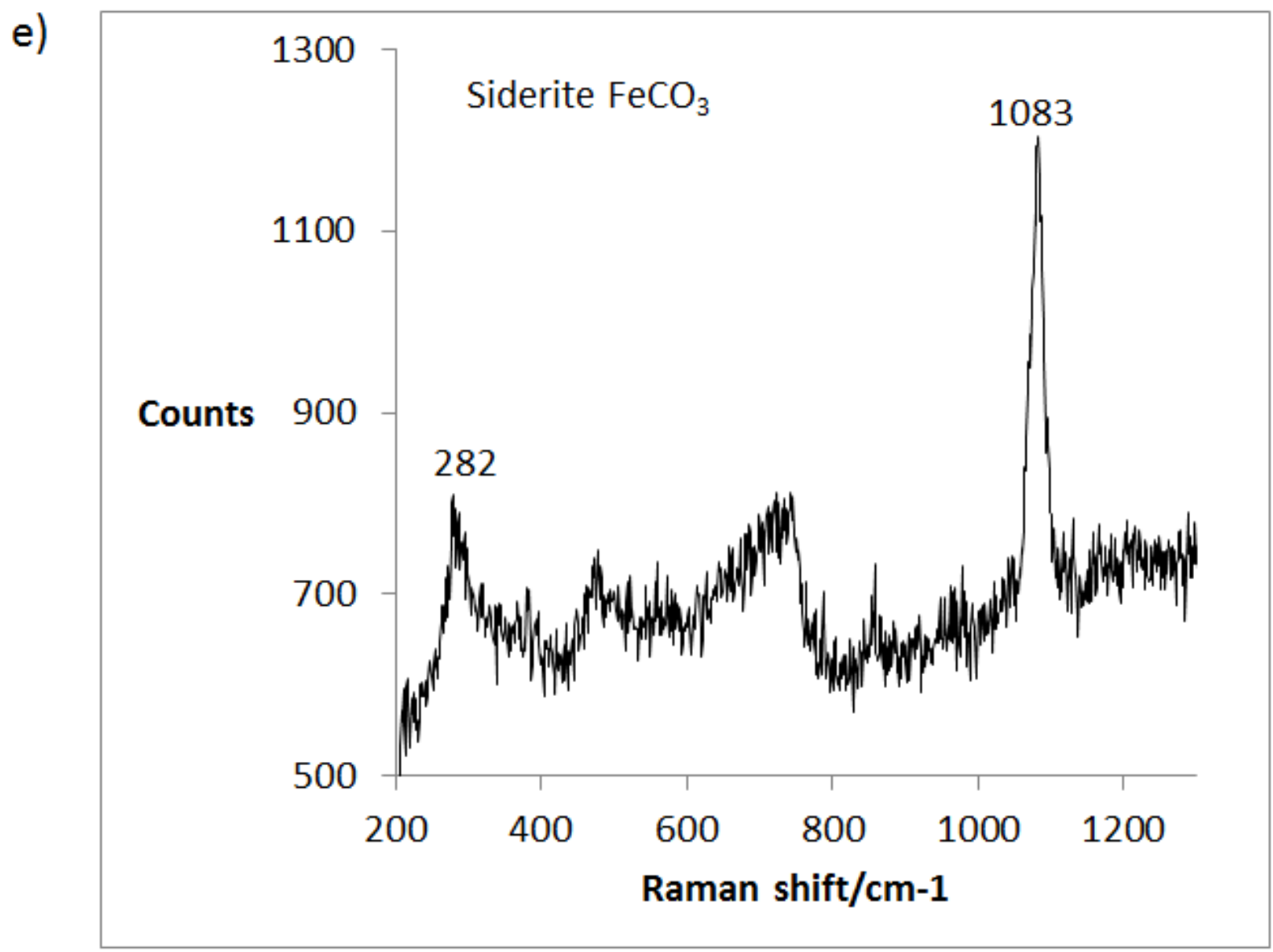


f)

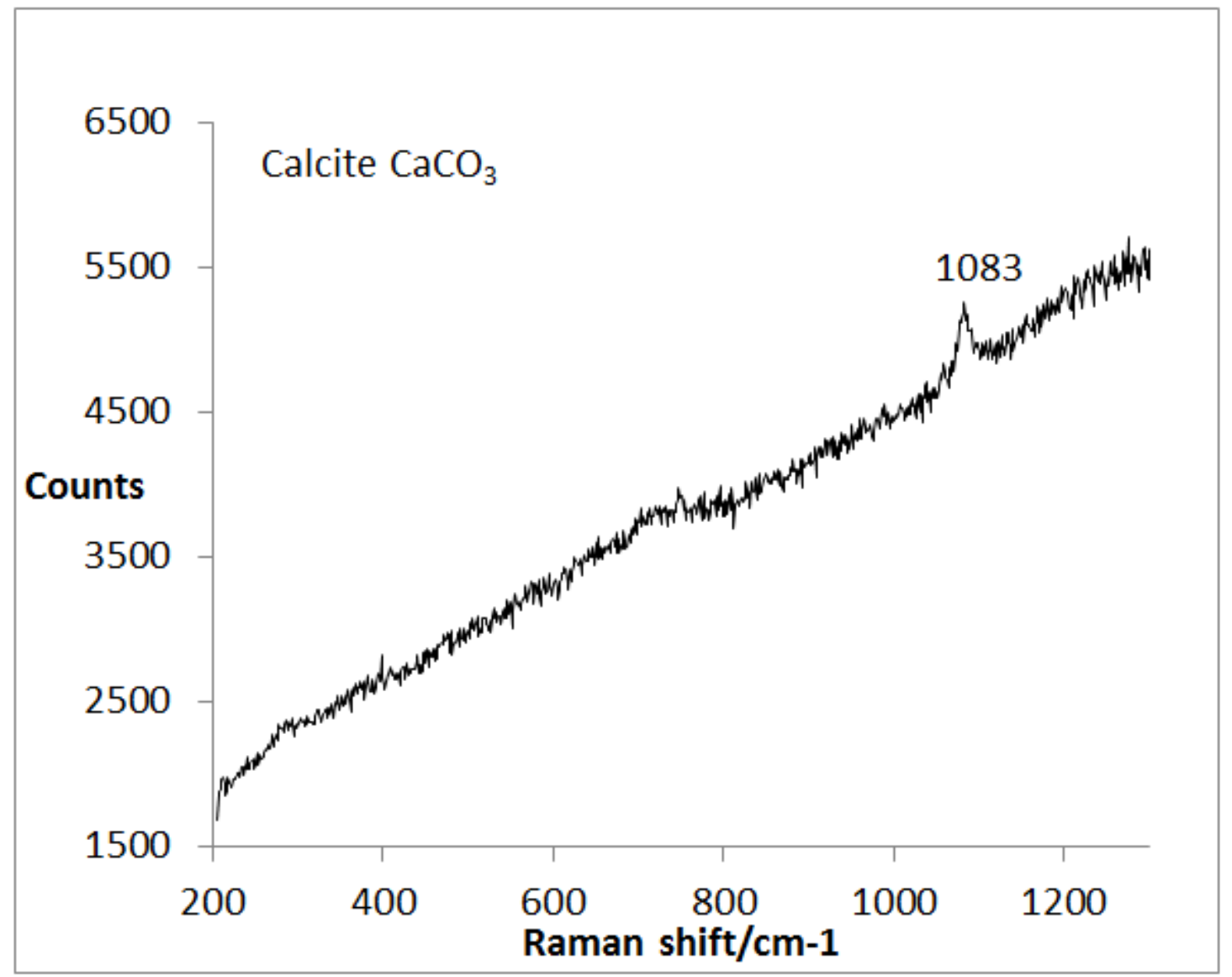

Figure 7-Archaeological nail GL07-35: $\mu$ RS maps corresponding to the optical micrograph of Figure 6. Distribution of chukanovite $\mathrm{Fe}_{2}(\mathrm{OH})_{2} \mathrm{CO}_{3}(\mathrm{a})$; siderite $\mathrm{FeCO}_{3}(\mathrm{~b})$; calcite $\mathrm{CaCO}_{3}$ (c) and their associated $\mu$ Raman spectra $(d, e, f)$.

C-AFM investigations in backside contact were performed on the zone (square on the optical micrograph - Figure 8a). The AFM topography and current images were collected simultaneously (Figures 8b and 8c) and a good correlation between the surface topography and the current is evident.

Figure $8 \mathrm{~d}$ shows the current profile obtained with an imposed voltage of $+500 \mathrm{mV}$ on the mapped zone on each side of the metal $(\mathrm{M}) / \mathrm{CPL}$. The part of the profile located in the metal presents various current values with a maximum of $2.5 \mathrm{nA}$. The current measured at this location is heterogeneous. 
In the CPL zone only composed of siderite and chukanovite, the current values are always lower than the detection limit $(50 \mathrm{fA})$. Indeed at $+500 \mathrm{mV}$ the $\mathrm{CPL}$ is behaving as a pure insulator. However, the electrical behaviour can change from insulating to conductive when materials with semi-conductor properties are submitted to a negative or positive voltage, such as semi-conductors in the Schottky contact configuration. Mativetsky et al. [23] have shown that under ambient conditions, graphene oxide, which is a semi-conductor, undergoes a sharp transition from an insulating to a conductive form, reduced graphene oxide ( $r G O)$, when a sufficiently large negative bias is applied between the C-AFM probe and the counter-electrode. With a sample voltage of $-1 \mathrm{~V}$ to $+1 \mathrm{~V}$ applied to this zone of the CPL, no current was measured excluding semi-conductor properties for ferrous carbonates, but rather an insulating behaviour was observed. 
a)

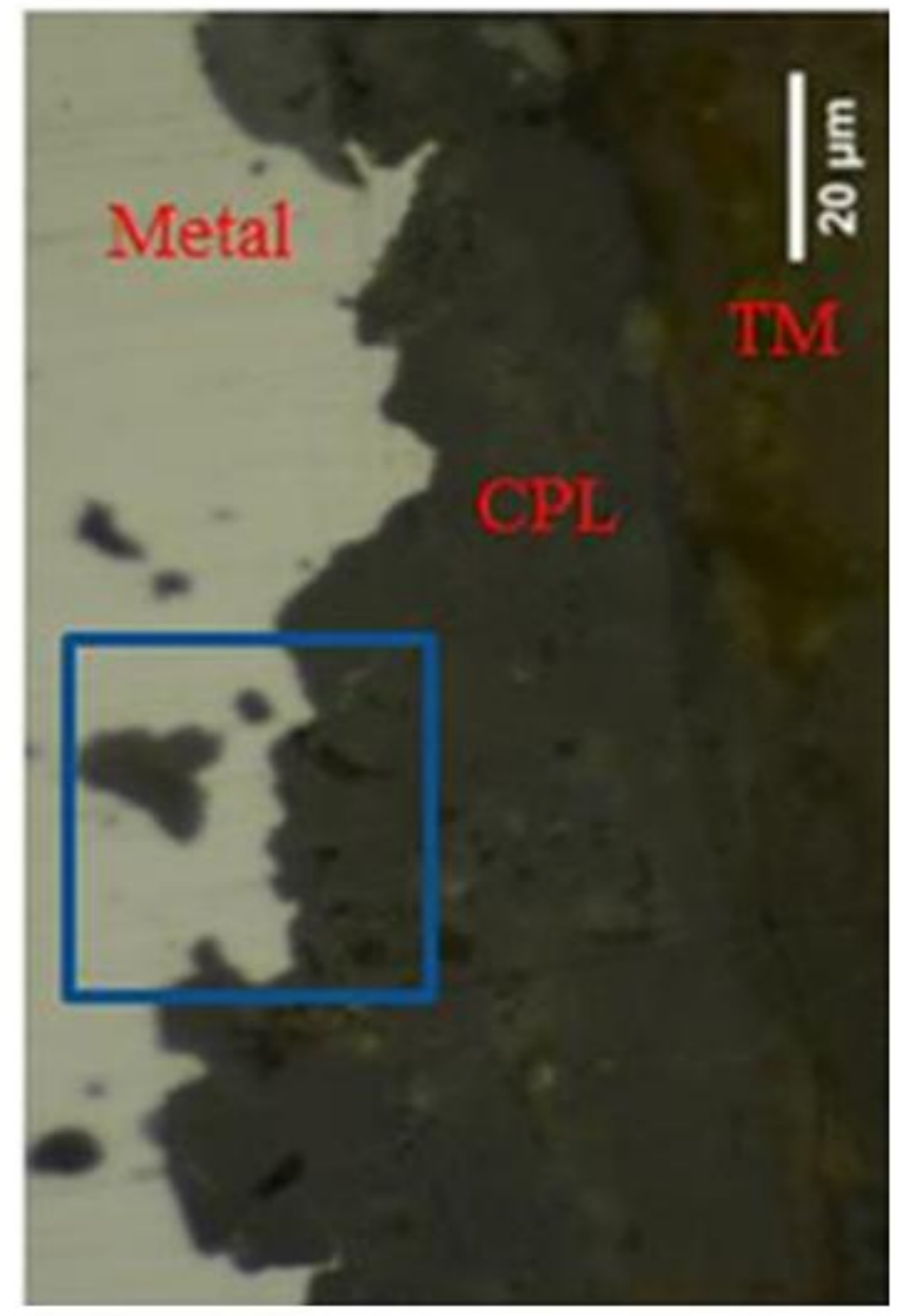

b)
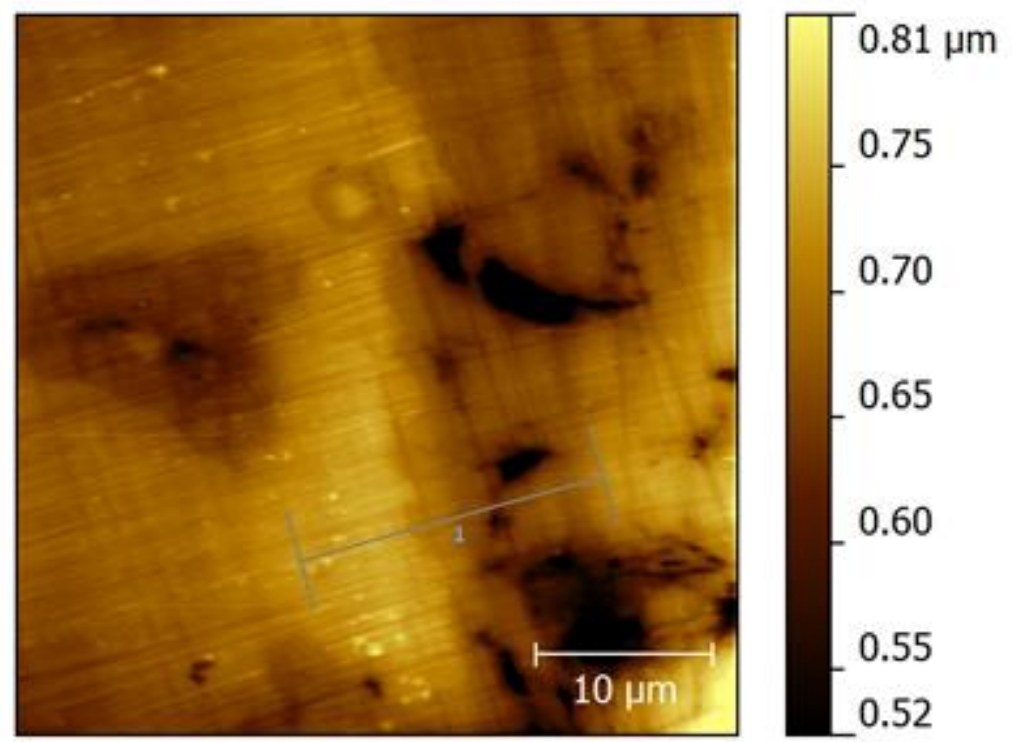
c)
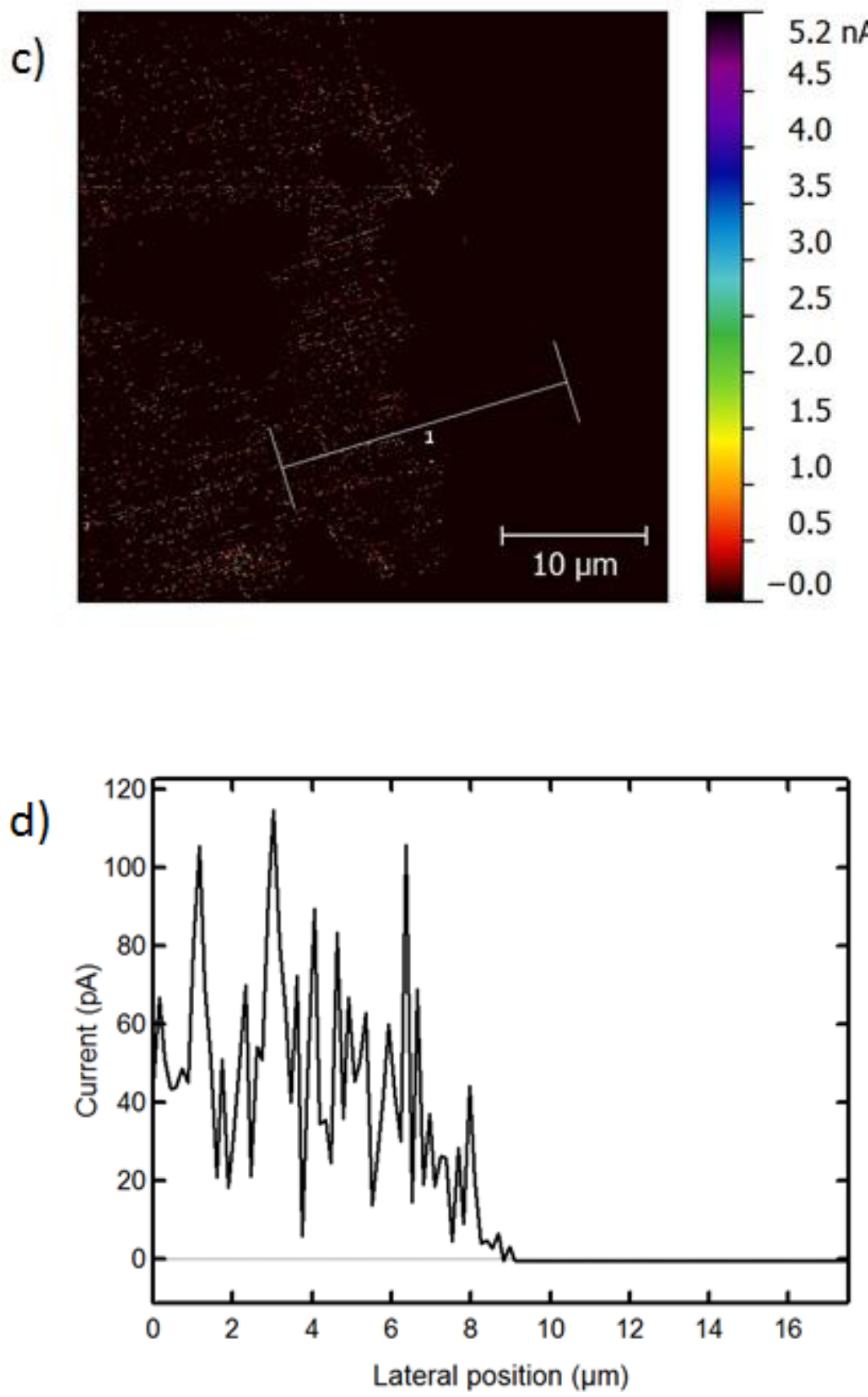

Figure 8 - Archaeological nail GL0735: optical micrograph (a), squared zone and its CAFM topography image (b), current image (c) and current profile between metal and CPL (d) (bias $=+500 \mathrm{mV}$, backside contact).

\subsection{Corrosion profiles with magnetite embedded inside the ferrous carbonate matrix}

\section{- Magnetite strips at the CPL/TM interface:}

Figure 9a displays an optical image representing a zone where the corrosion product layer is composed of siderite $\mathrm{FeCO}_{3}$ as indicated by Raman spectra obtained at this location 
(main peak at $1080 \mathrm{~cm}^{-1}$ - Figure 9b). A brighter strip is observed in the CPL. The $\mu$ Raman spectrum obtained from this strip corresponds to magnetite $\mathrm{Fe}_{3} \mathrm{O}_{4}$, which is well characterized by its main Raman signal at $671 \mathrm{~cm}^{-1}$ (Figure 9c). Between the magnetite strip and the metal, In the outer zone of the magnetite strip, the presence of calcite $\mathrm{CaCO}_{3}$ revealed by the Raman spectrum and its very narrow carbonate peak at $1086 \mathrm{~cm}^{-1}$ signals the TM (Figure 9d). Therefore, the magnetite strip is located at the CPL/TM interface, as is often the case for iron archaeological artefacts corroded long-term in carbonated anoxic environments [4-7].

a)

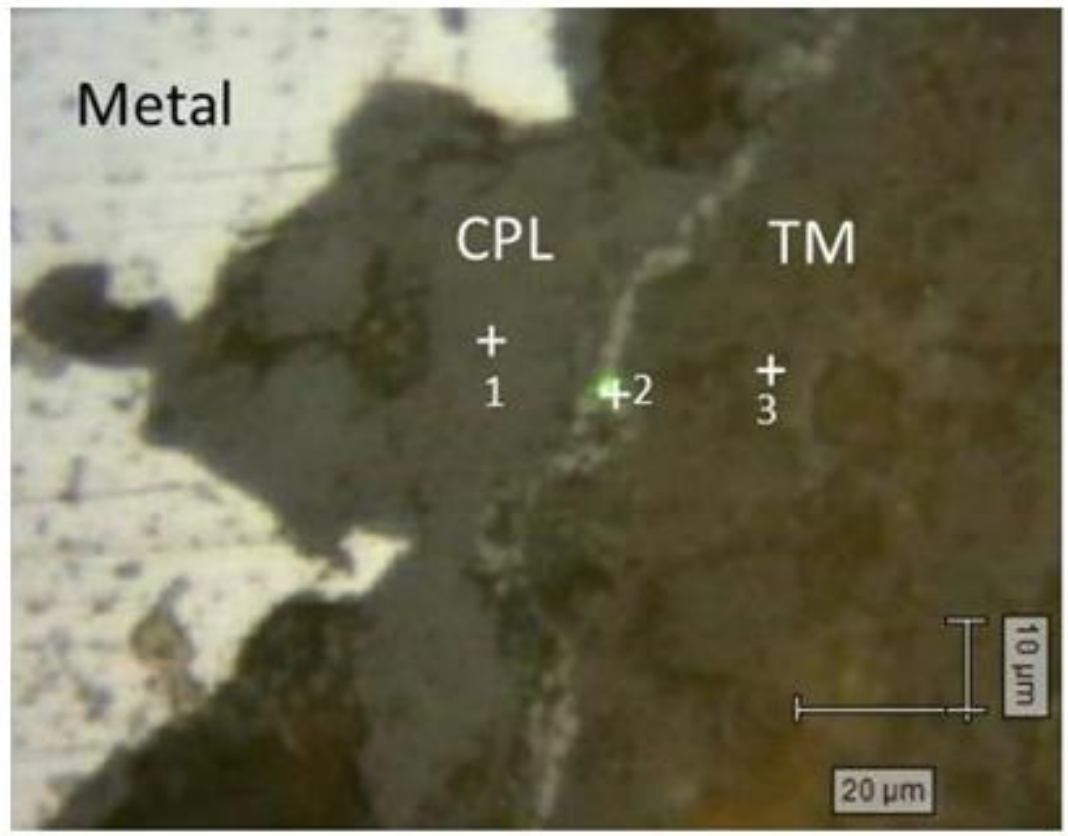


b)

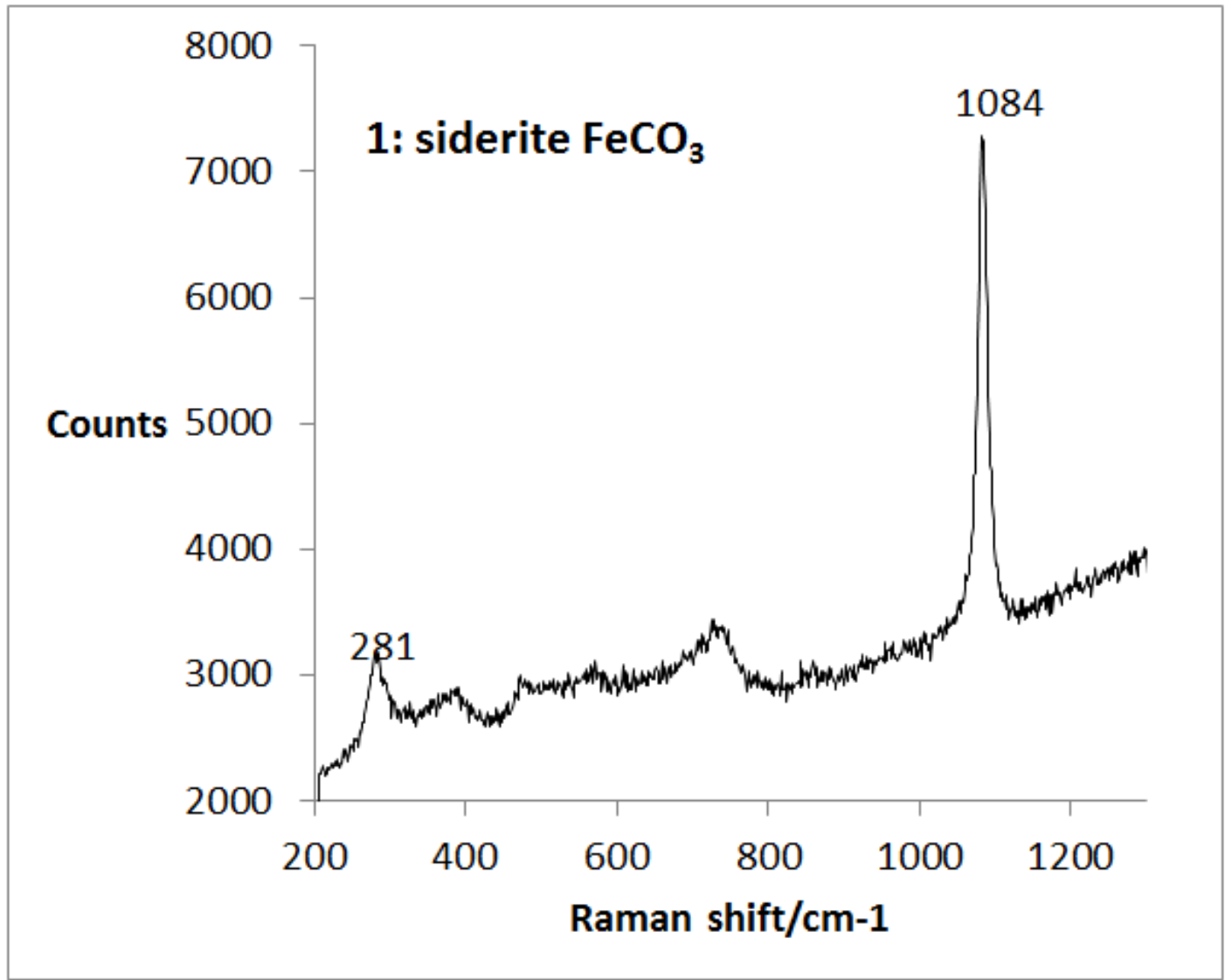


c)

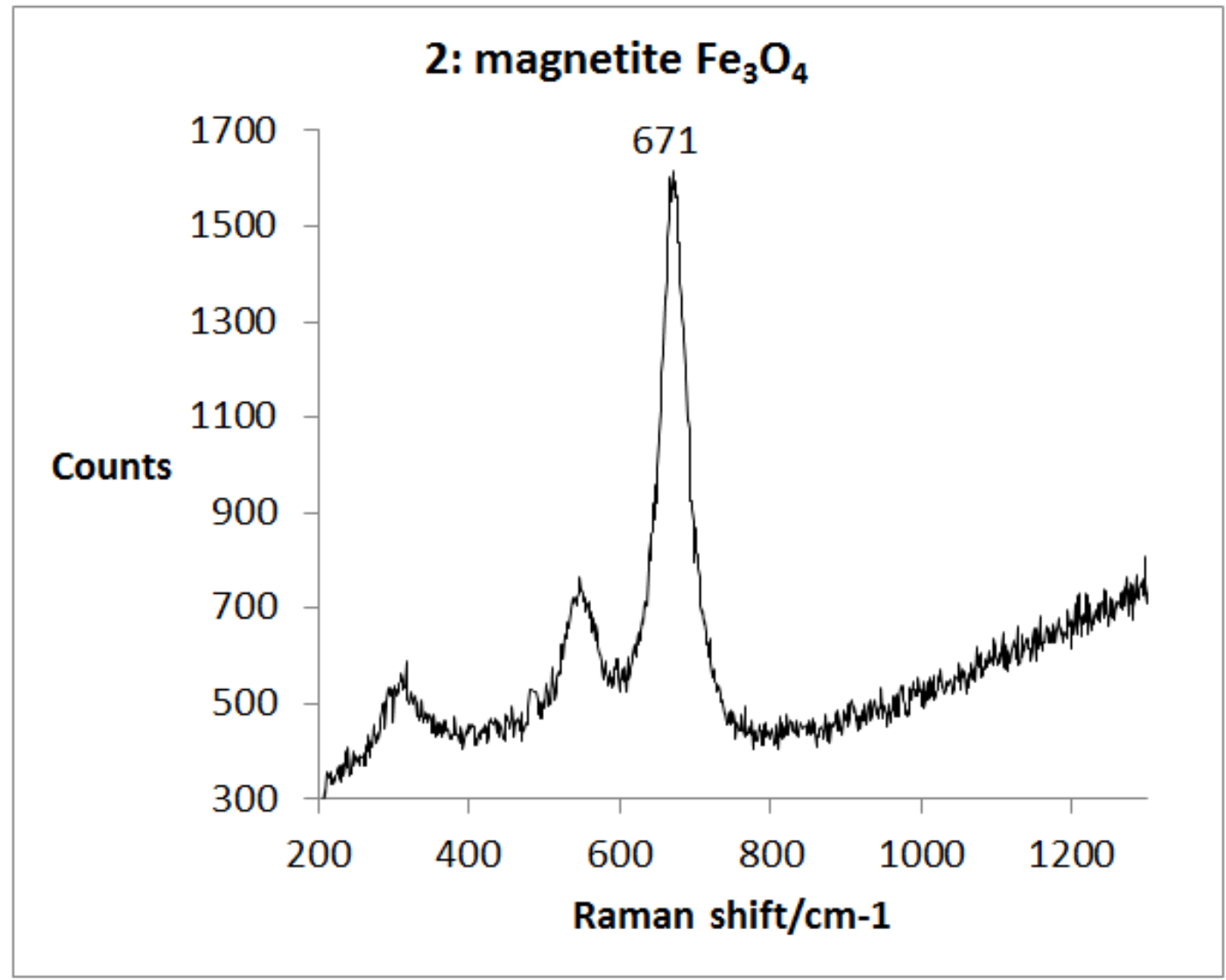


d)

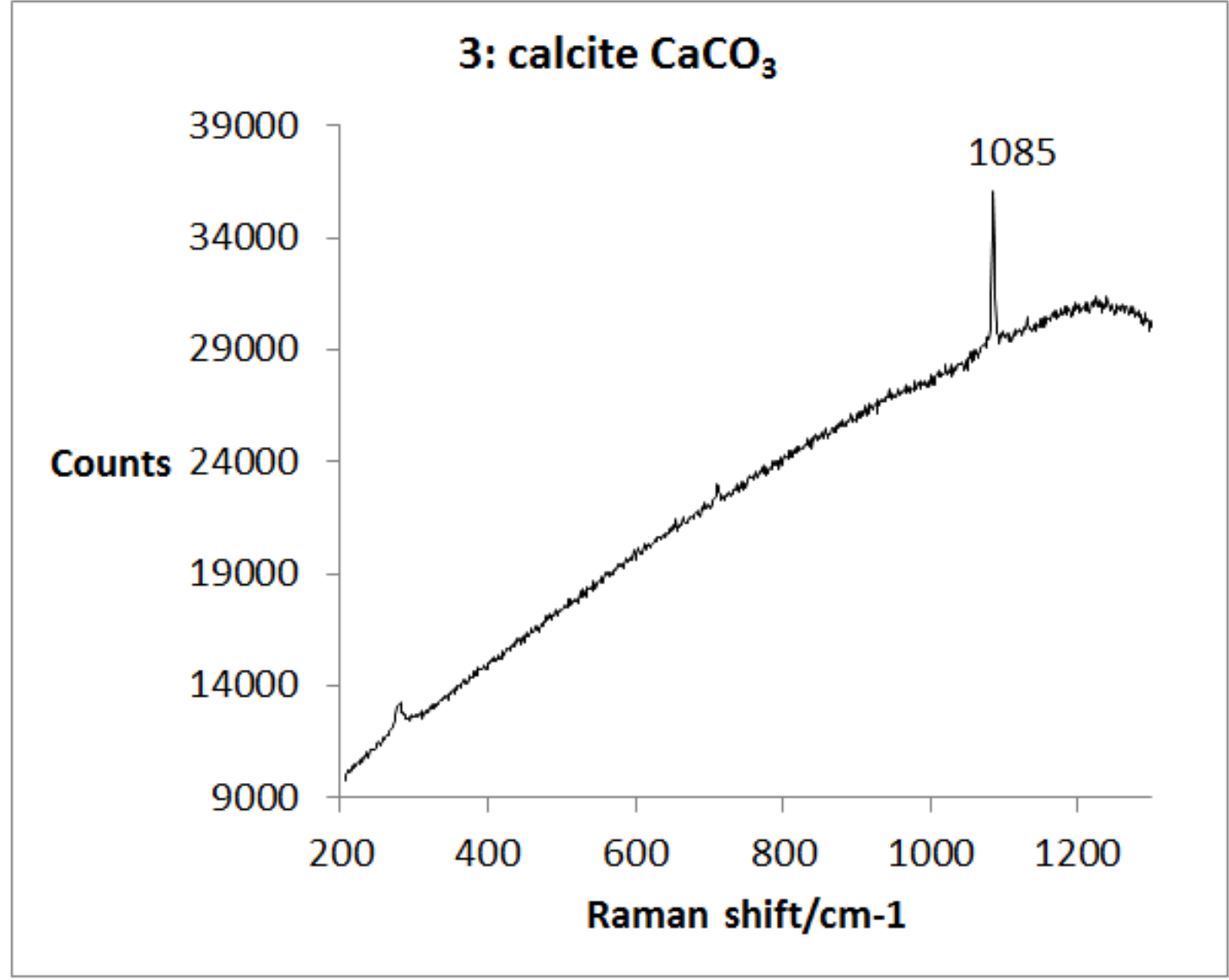

Figure 9 - Archaeological nail GL12-72: optical micrograph (a) and $\mu$ Raman spectra corresponding to the different zones in the $\mathrm{CPL}$ and in the TM $(b, c, d)$.

Siderite $\mathrm{FeCO}_{3}(1)$, magnetite $\mathrm{Fe}_{3} \mathrm{O}_{4}(2)$ and calcite $\mathrm{CaCO}_{3}(3)$.

A surface of $40 \mu \mathrm{m} \times 40 \mu \mathrm{m}$ across the magnetite strip was mapped by C-AFM. An initial experiment was performed with backside contact geometry. A topography image (Figure 10a) was simultaneously collected with the current image (Figure 10b). First, it is interesting to note the high correlation between the surface morphology and the electrical measurement. Secondly, the current image indicates a maximal value of $4.5 \mathrm{nA}$ for magnetite, contrary to the rest of the CPL that did not show any measurable current. In addition, a smaller surface, $5.2 \mu \mathrm{m} \times 5.2 \mu \mathrm{m}$, of the magnetite strip was mapped in topography (Figure 11a) and in current (Figure 11b). The current image clearly shows that the magnetite strip is discontinuous with current heterogeneity. 
These measurements confirmed the insulating character of both the CPL and the TM. Concerning magnetite, the out-of-plane geometry (see Figure 2) does not confirm that this phase is connected to the iron metallic substrate.

a)

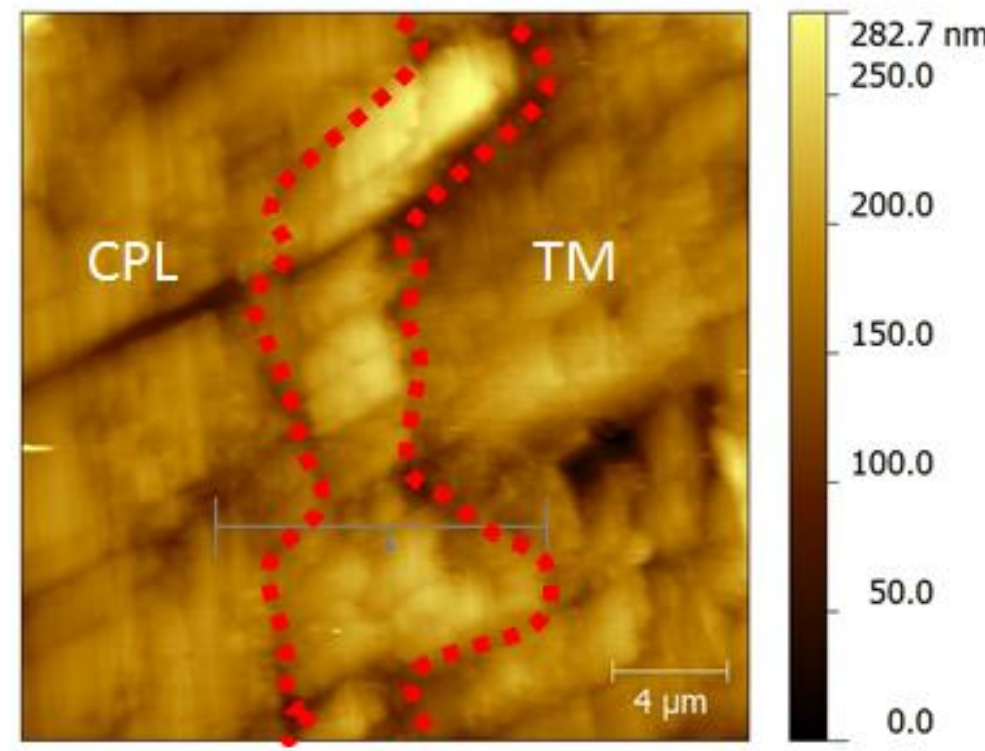

b)

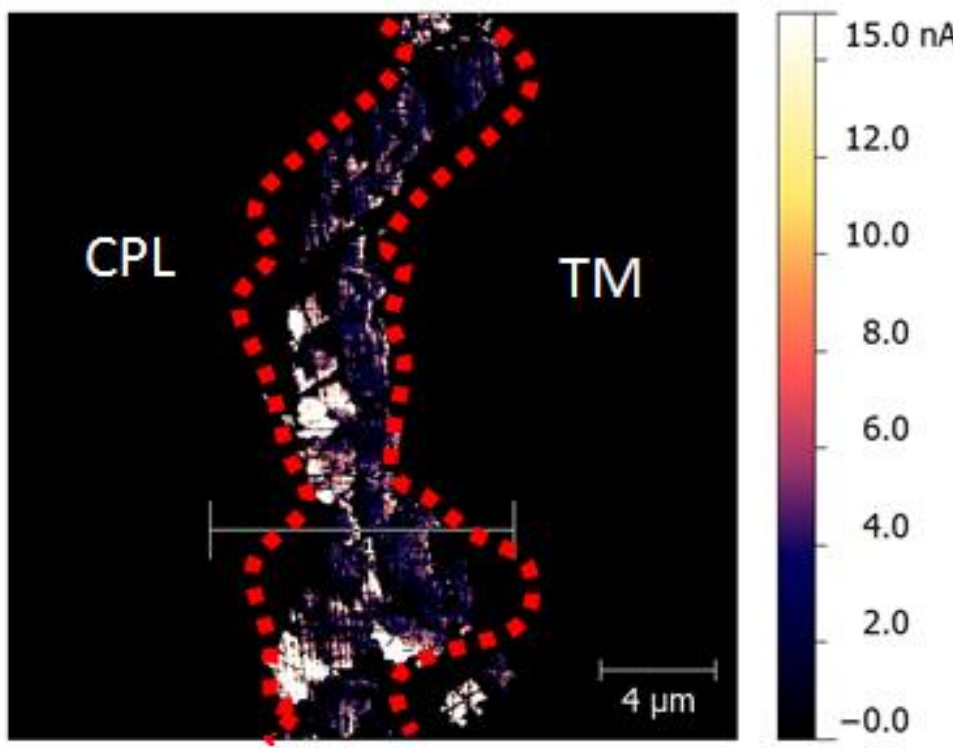


c)

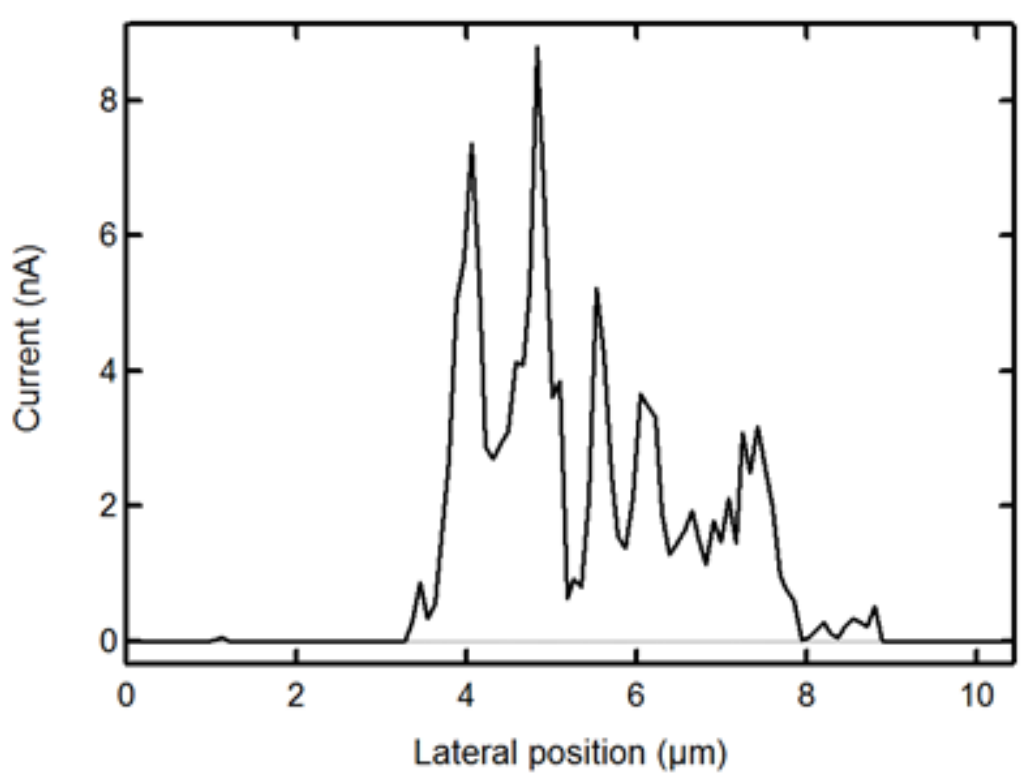

Figure 10 - Archaeological nail GL12-72: C-AFM topography image (a) current image (b) of $40 \mu \mathrm{m} \times 40 \mu \mathrm{m}$ across the magnetite strip and current profile (c) (bias $=+500 \mathrm{mV}$, backside contact).

a)
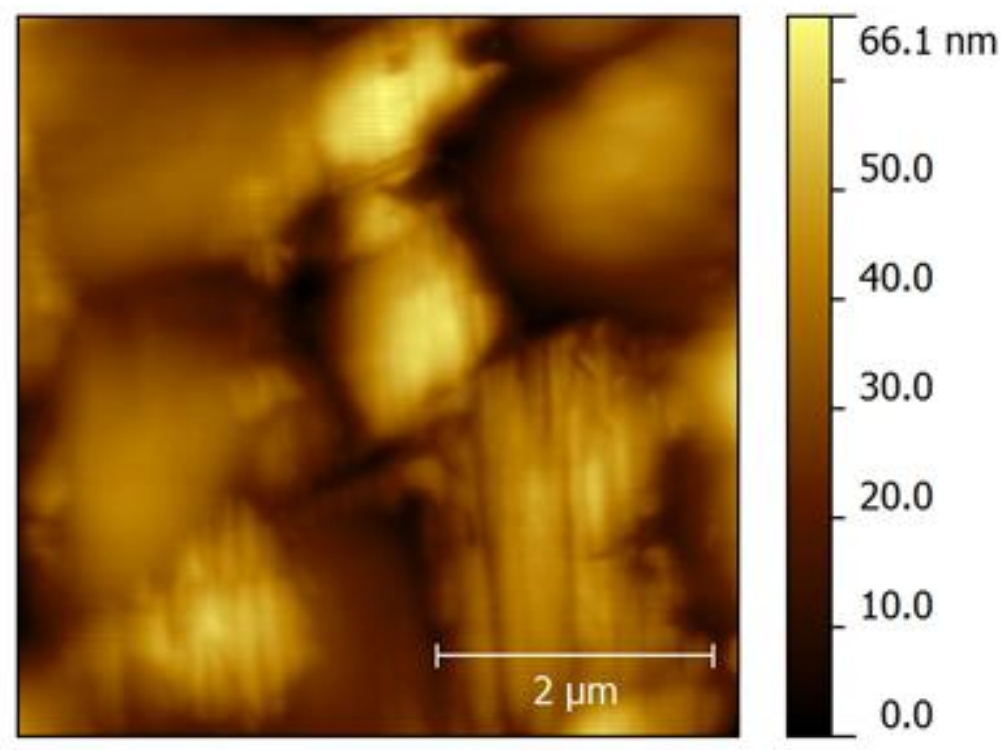
b)

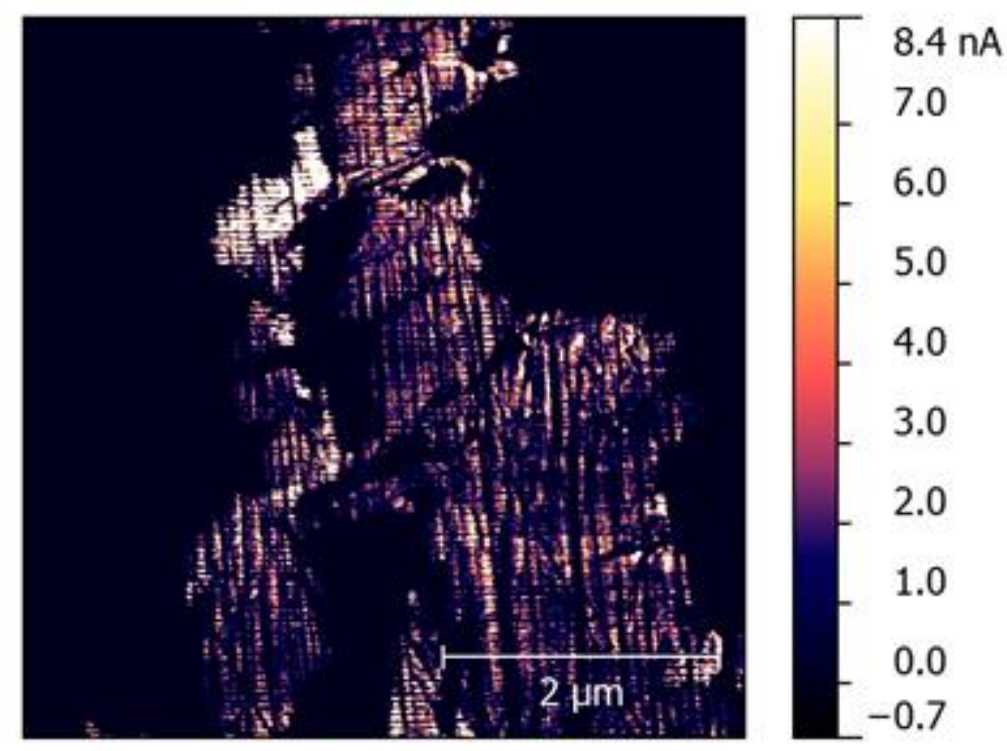

Figure 11 - Archaeological nail GL12-72: C-AFM topography image (a) and current image (b) of the magnetite strip evident on the previous C-AFM image (bias $=+500 \mathrm{mV}$, backside contact).

To determine the electron conduction channels inside the CPL by measuring the in-plane current, C-AFM in front side contact geometry was conducted to map the same zone. In this configuration, the C-AFM images (Figures 12a and 12b) show that the magnetite strip presents a heterogeneous and significant current, suggesting the existence of a lateral bulk conduction channel. As in this mapped zone, the magnetite strip is not directly connected to the metal on the observable surface (see the optical micrograph Figure 9a). These measurements could suggest the connectivity of magnetite strips to the metal in the bulk of the CPL. 
a)

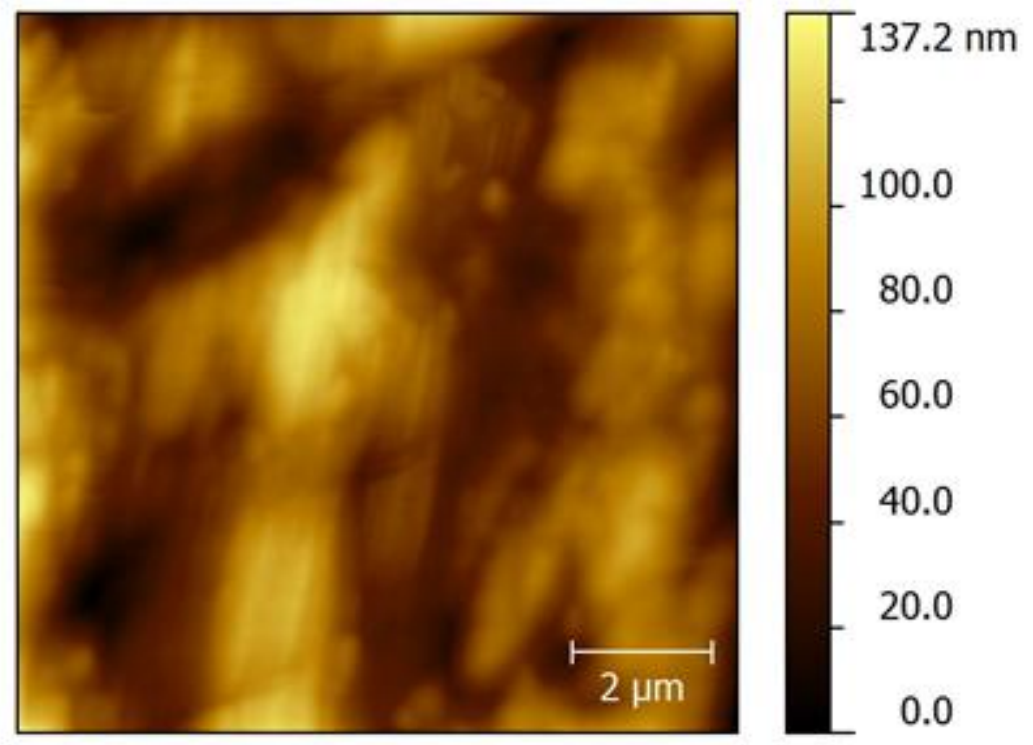

b)

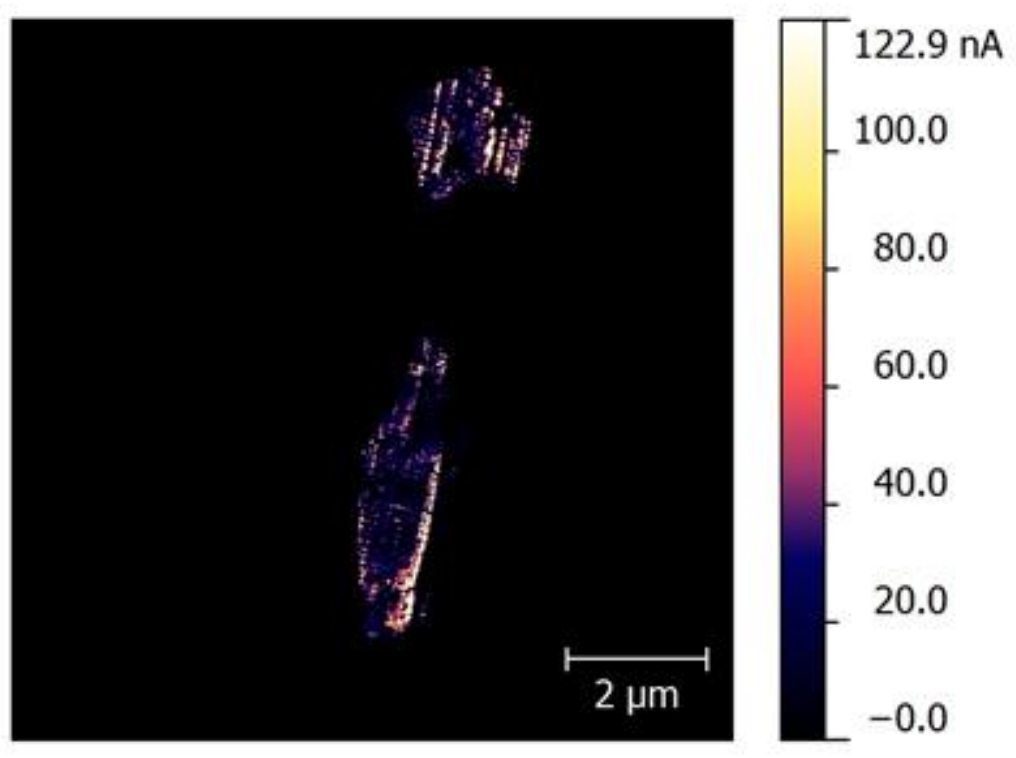

Figure 12 - Archaeological nail GL12-72: C-AFM topography image (a) and current image (b) of $10 \mu \mathrm{m} \times 10 \mu \mathrm{m}$ across the magnetite strip (bias $=+500 \mathrm{mV}$, front side contact). 


\section{- Magnetite islets in the CPL carbonate matrix:}

A third corrosion profile observed in the archaeological artefacts from Glinet corresponds to magnetite islets, completely embedded in the CPL and made of Fe" carbonates. Figure 13a displays the optical micrograph of this type of corrosion profile, archaeological nail GL $12-72$ at X50 magnification. As for the previous profile, magnetite strips can be observed at the CPL/TM interface as well as in the form of nodules of several microns embedded in the CPL matrix. This CPL matrix is made of siderite as shown by the Raman spectra collected at this location (Figure 13b). Spectra collected of the islets show a less intense signal with a broad band at $\sim 660 \mathrm{~cm}^{-1}$ corresponding to a poorly crystallized magnetite (Figure 13c). The peak of siderite at $1080 \mathrm{~cm}^{-1}$ is also evident on this spectrum.

C-AFM topography and current images were obtained for the transverse section in a zone of the CPL containing such magnetite islets (Figure 14), marked ' 2 ' on the optical micrograph in Figure 13a. The C-AFM topography image is heterogeneous and shows significant differences between the carbonate matrix and the magnetite. The magnetite topography is homogenous and its nodule can be precisely located. It is characterized by higher current values. This shows that the magnetite nodules are connected to the metallic substrate, even if they are trapped in an insulating siderite matrix. It is interesting to note that for the same voltage, the current values in the magnetite strips are lower than those measured in the magnetite nodules (some tens of $\mathrm{pA}$ and hundreds of $\mathrm{pA}$ respectively). 
a)

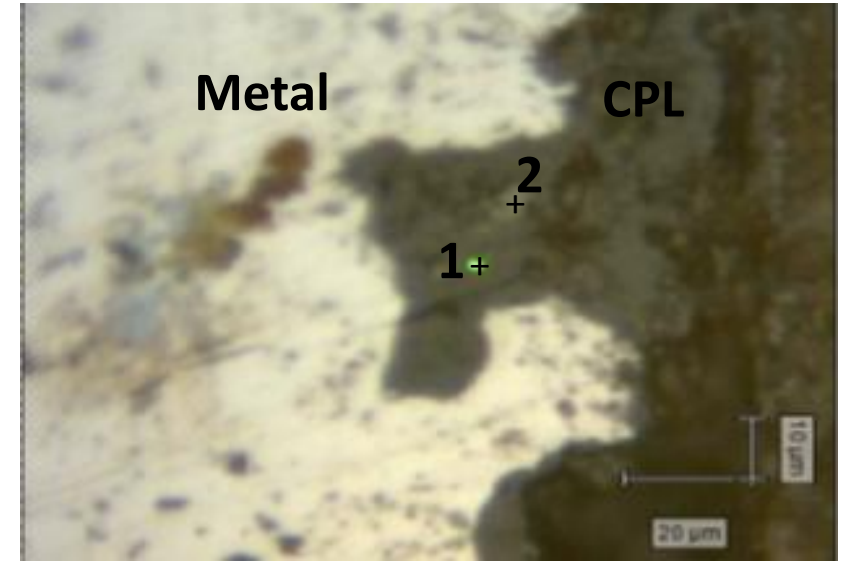

b)

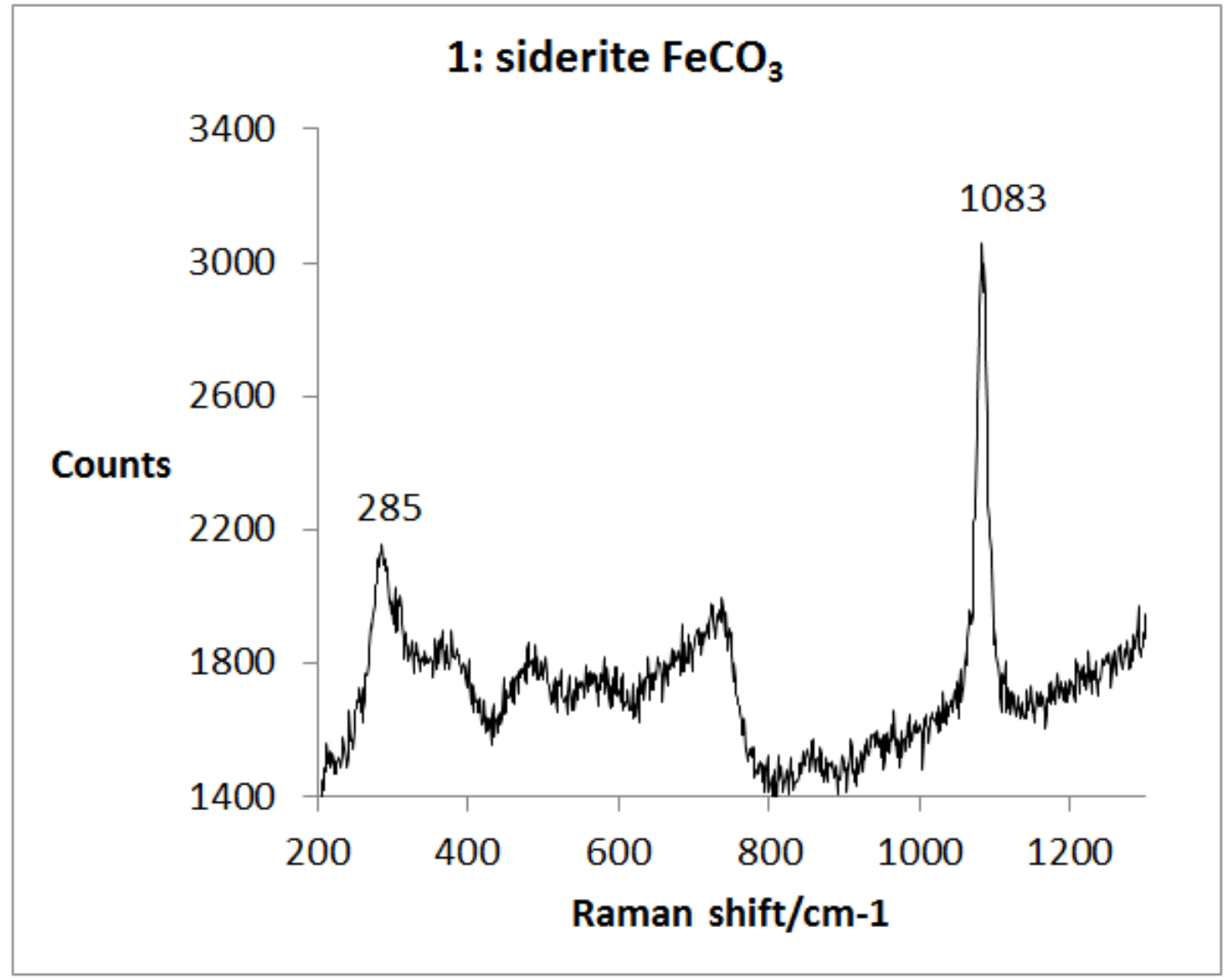


c)

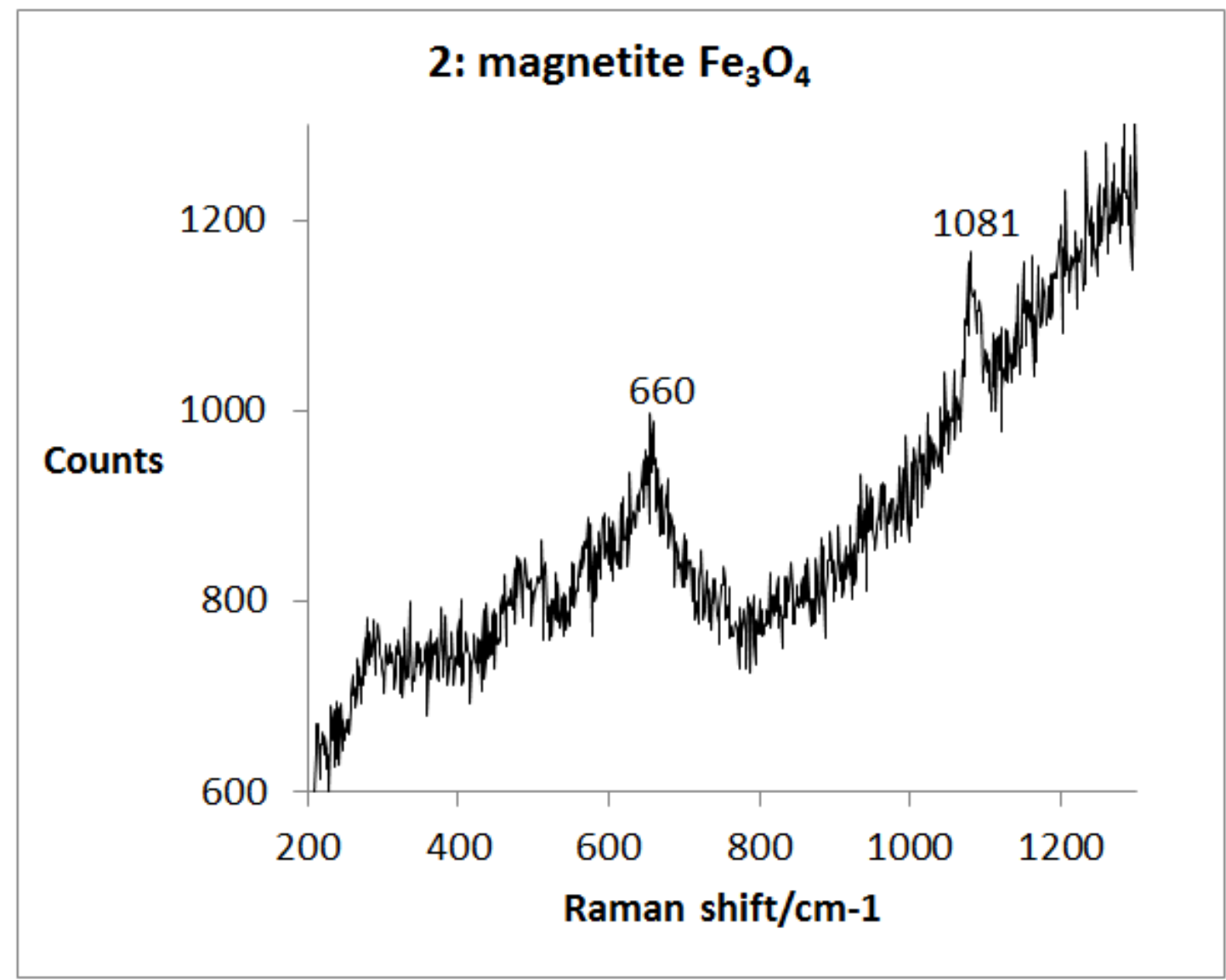

Figure 13 - Archaeological nail GL1272: optical image at X50 (a) and $\mu$ Raman spectra (b and c). Siderite $\mathrm{FeCO}_{3}$ (b) and poorly crystallized magnetite $\mathrm{Fe}_{3} \mathrm{O}_{4}$ (c).

a)

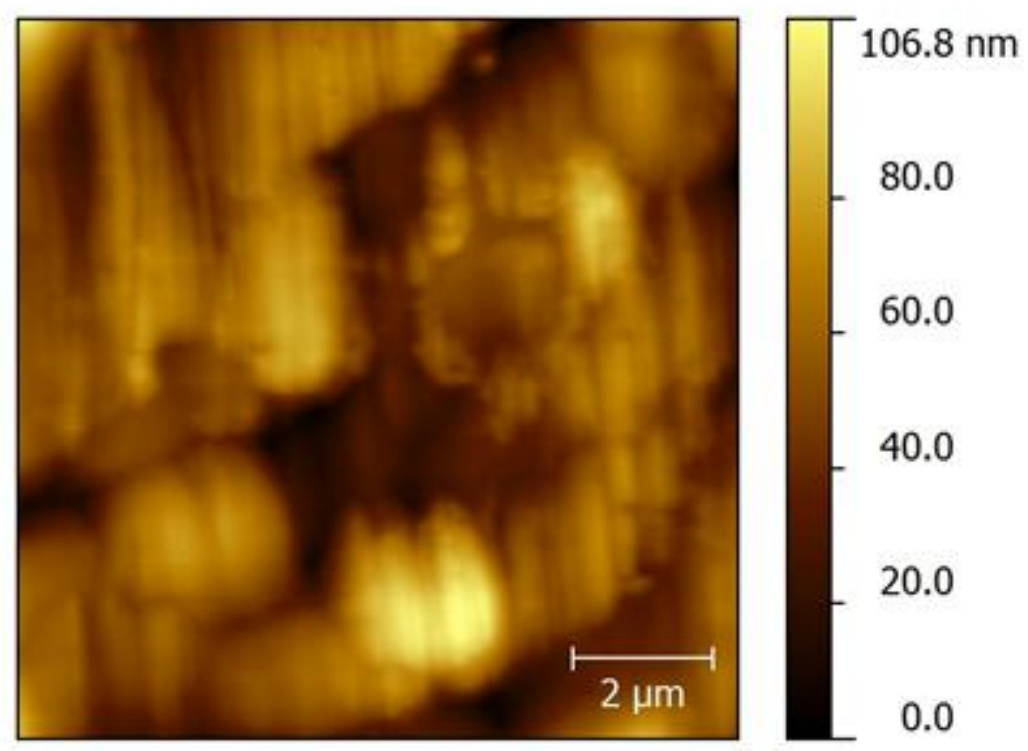




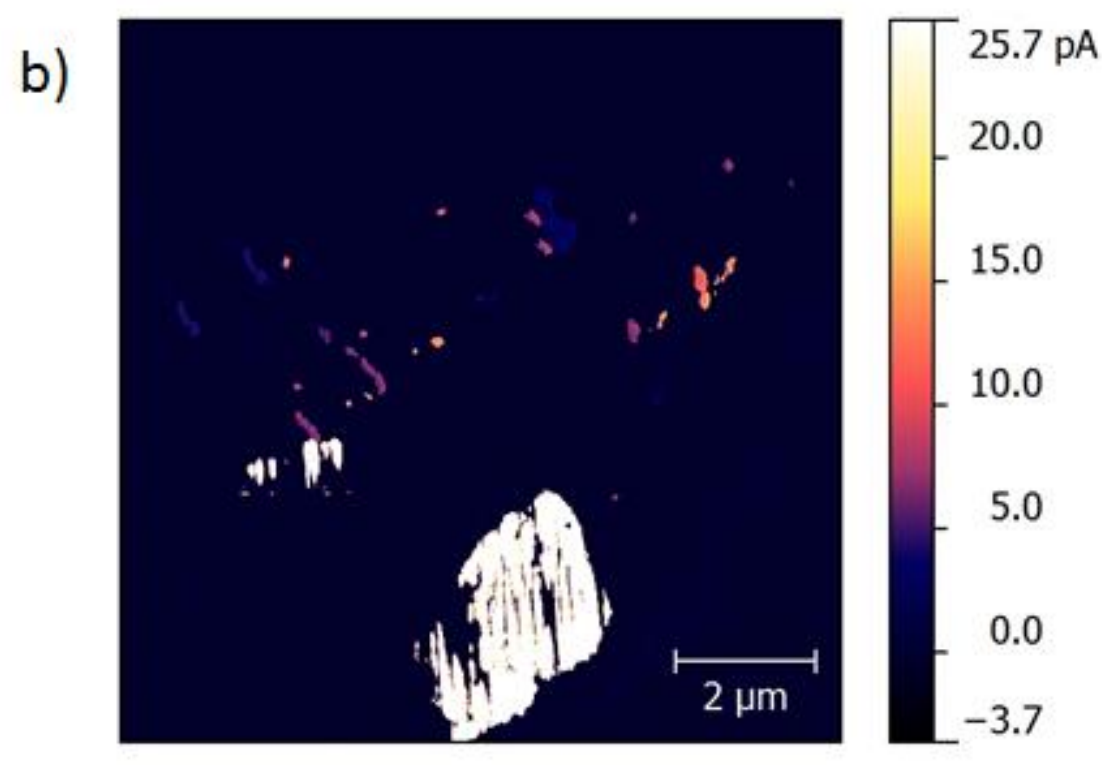

Figure 14 - Archaeological nail GL12-72: C-AFM topography image (a) and current image (b) across the magnetite nodule. The corresponding nodule is the point 2 on the Figure 10a (bias $=+500 \mathrm{mV}$, front side contact).

\subsection{Corrosion profiles containing iron sulfides.}

In addition to the presence of the main ferrous carbonate compounds (siderite and chukanovite) and magnetite, iron sulfide islets can be also present in the CPL of the archaeological nails as shown on the optical micrographs, at two magnifications, of the CPL (Figure 15). These phases are present at the TM/CPL interface or mixed in the ferrous carbonate matrix. Their crystalline nature was determined by $\mu$ Raman and a diversity of iron sulfides was revealed. Spectrum 1 indicated a mix of mainly crystalline mackinawite $\mathrm{FeS}_{1-\mathrm{x}}$ (main peak at $301 \mathrm{~cm}^{-1}$ ) as well as some greigite $\mathrm{Fe}_{3} \mathrm{~S}_{4}$ (main peak at $357 \mathrm{~cm}^{-1}$ ). Spectrum 2 also corresponds to a mix of greigite and crystalline mackinawite. This diversity of iron sulfides supports the findings of previous studies on the same type of artefacts $[9,24]$. The presence of the ferrous carbonate matrix of the CPL is also indicated by the presence of the Raman peak at $1083 \mathrm{~cm}^{-1}$ of siderite $\mathrm{FeCO}_{3}$ on spectrum 1. 
a)

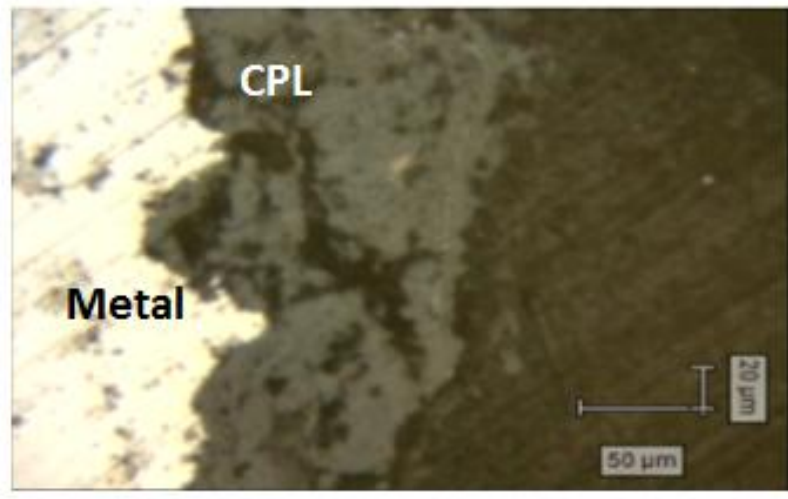

b)

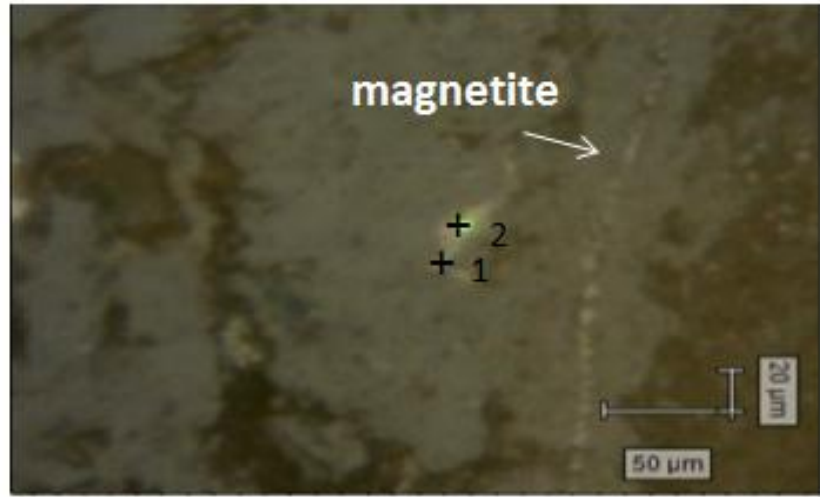

c)

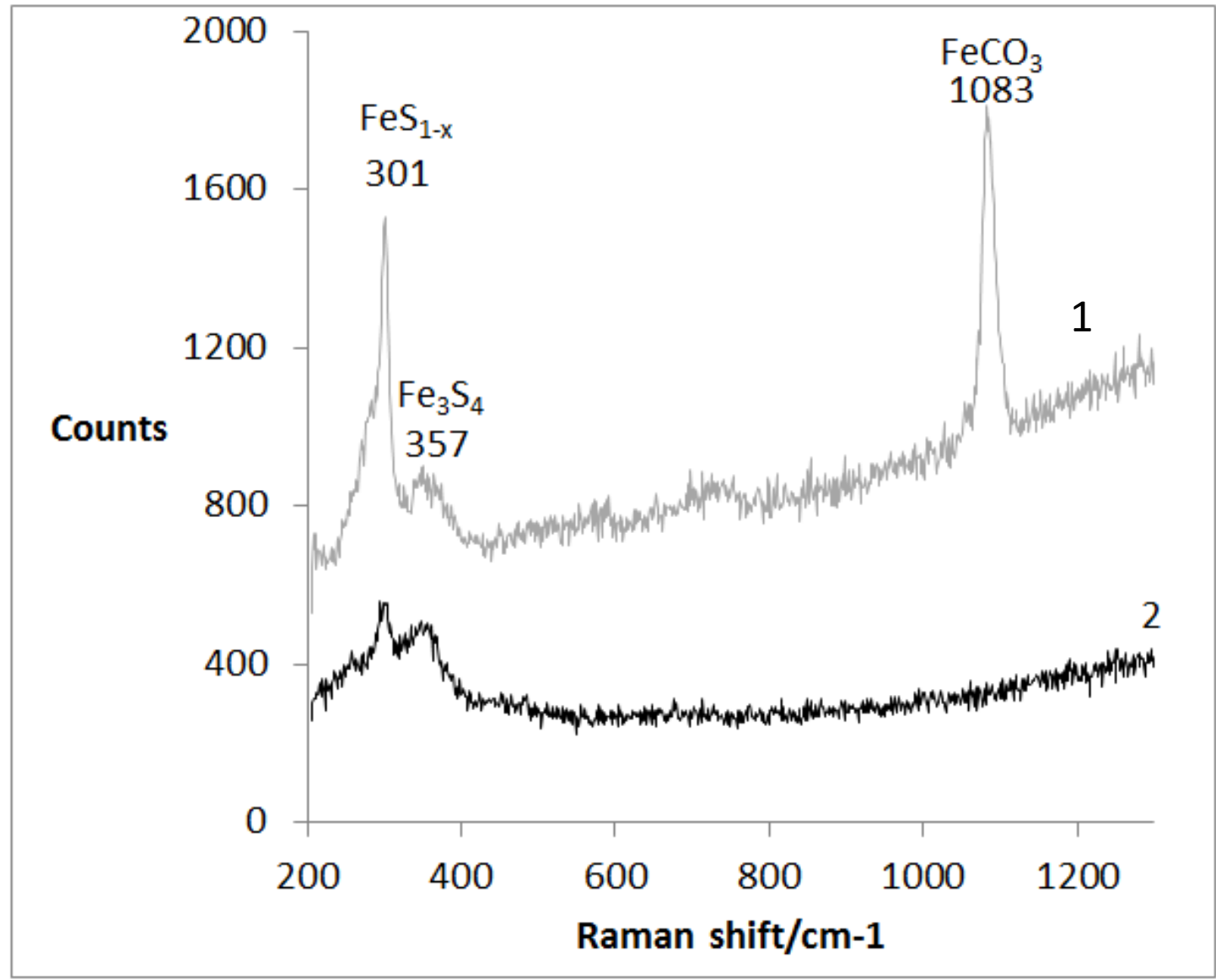

Figure 15 - Archaeological nail GL12-72: optical micrographs of the CPL at two magnifications with the presence of iron sulfide islets and $\mu$ Raman spectra for the determination of their crystalline nature (1: mix of crystalline mackinawite $\mathrm{FeS}_{1-\mathrm{x}}$ /greigite $\mathrm{Fe}_{3} \mathrm{~S}_{4}$ with mainly mackinawite; 2 : mix of crystalline mackinawite $\mathrm{FeS}_{1-x}$ and greigite $\mathrm{Fe}_{3} \mathrm{~S}_{4}$ ).

The optical micrograph, the C-AFM images and the current profile curve obtained from the front side contact geometry are presented in Figures 16a, 16b, 16c and 16d respectively. The current image (Figure 16c) exactly follows the iron sulfide shape 
observed on the optical micrographs of the CPL displayed in Figure 16a. From the current profile curve, the maximal current value of this iron sulfide can reach $4 \mathrm{pA}$.

From the current profile curve, the magnetite strip situated near the sulfide zone also shows similar significant current values up to $2 \mathrm{pA}$. Between the iron sulfide islet and the magnetite strip, the carbonate matrix of the CPL is clearly shown to be isolating. The fact that significant current values were measured in the iron sulfides suggests that these phases are conductive and connected to the metal, despite being embedded in an isolating $\mathrm{Fe}^{\text {II }}$ carbonate matrix. The similarity of the current values for magnetite and iron sulfides (Figures $16 \mathrm{c}$ and $16 \mathrm{~d}$ ) indicate that these phases have similar electrical resistivity which corresponds to the data reported in the literature for these semiconductors: between $10^{-3}$ and $5 \times 10^{-3} \Omega . \mathrm{cm}$ for iron sulfides and between $10^{-3}$ and $10^{-2}$ $\Omega . c m$ for magnetite [25-27].

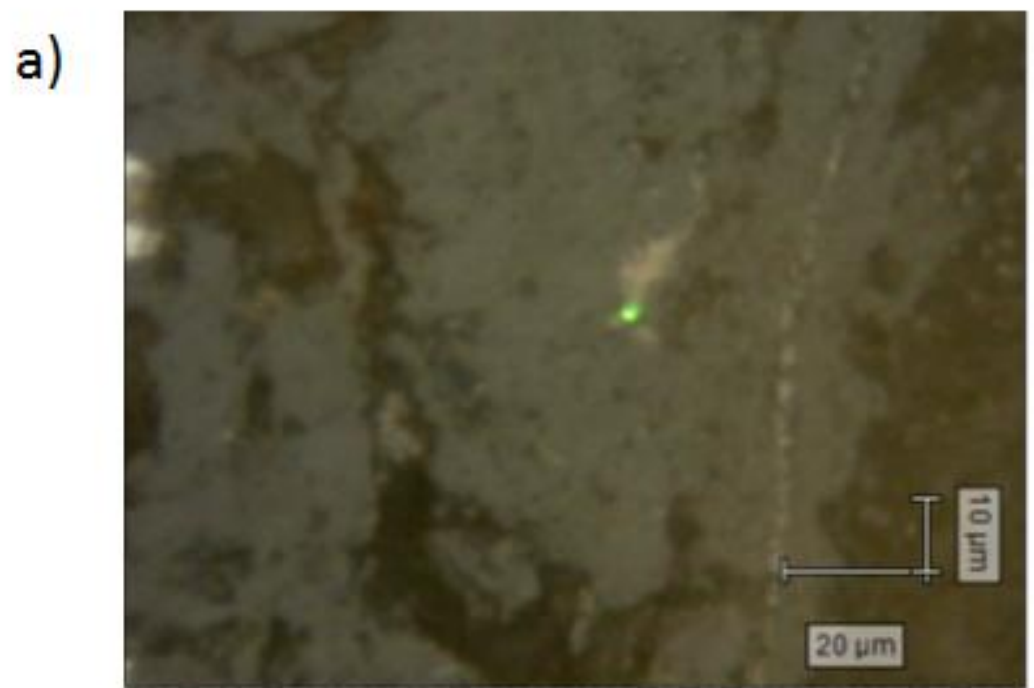


b)

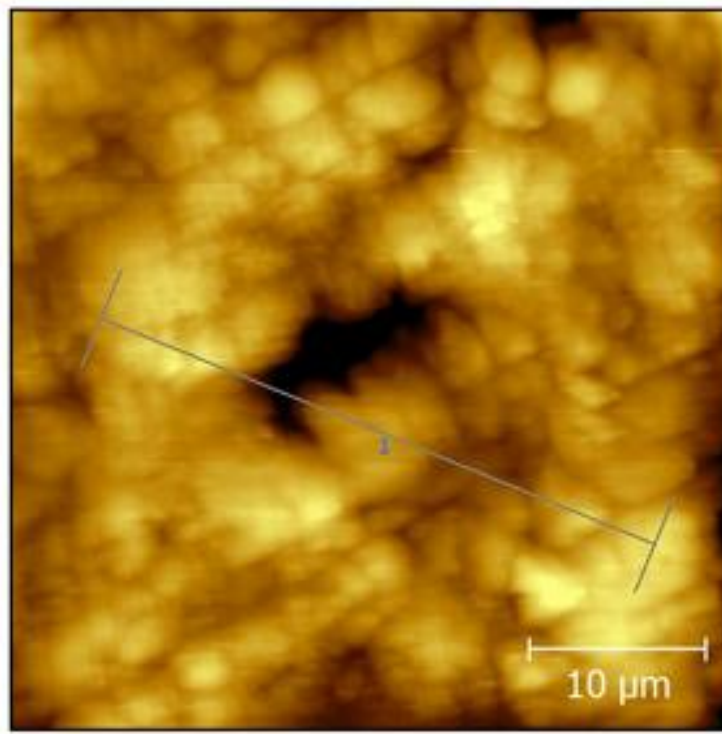

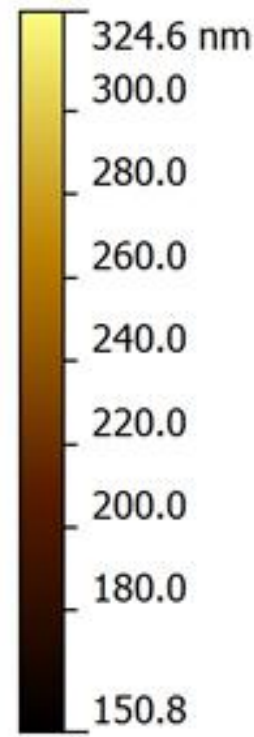

c)

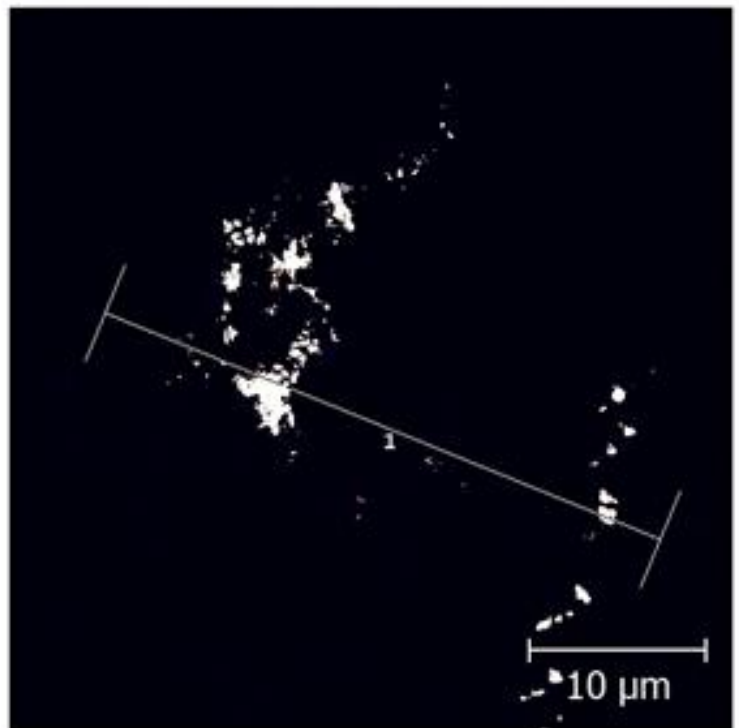




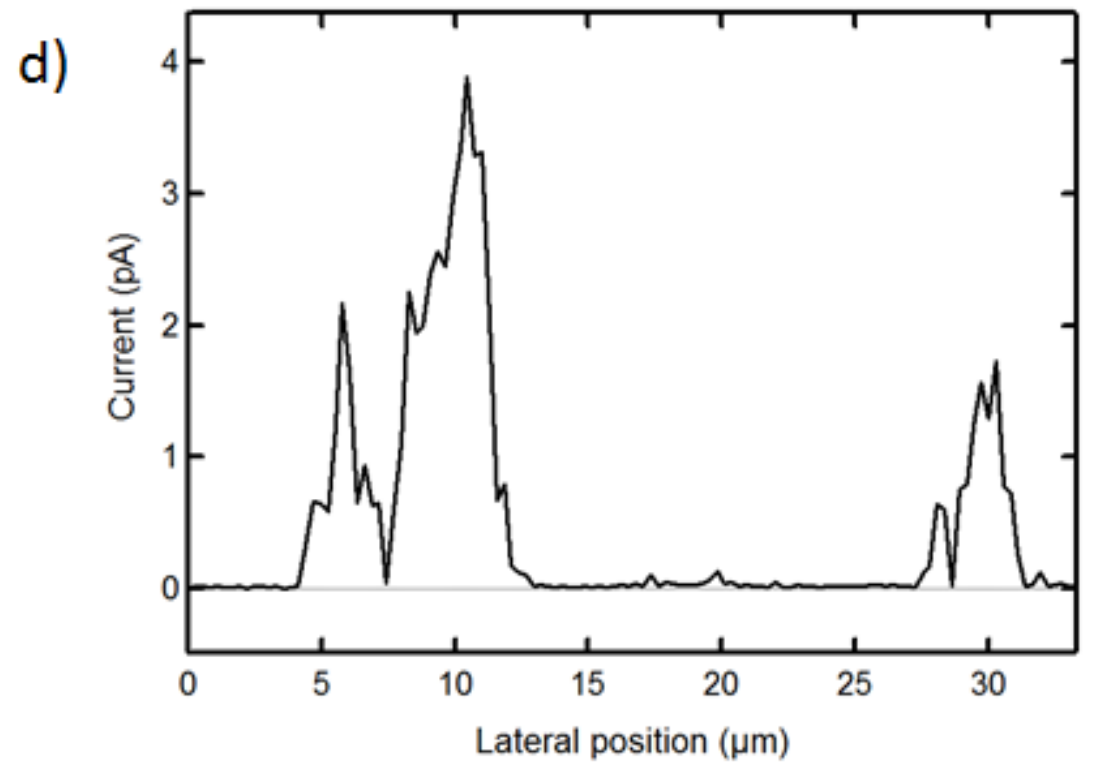

Figure 16 - Archaeological nail GL12-72: Optical image with iron sulfides and magnetite strip (a), C-AFM topography image (b), current image (c) and current profile curve (d) for a diversity of phases present in the CPL (ferrous carbonates, magnetite strips, iron sulfides) in the CPL (bias $=+500 \mathrm{mV}$, front side contact).

\section{Discussion}

Table 1 reports the corrosion patterns obtained from the corrosion systems observed on the archaeological artefacts and their electronic properties established by C-AFM. 
Table 1 - Summary of the corrosion patterns obtained by $\mu$ Raman of the different iron nails with their electronic properties established by C-AFM.

\begin{tabular}{|c|c|}
\hline $\begin{array}{l}\text { Description of the corrosion pattern } \\
\text { observed on cross section }\end{array}$ & Electronic properties of the CPL \\
\hline $\begin{array}{l}\text { Ferrous carbonates only: siderite } \mathrm{FeCO}_{3} \\
\text { and chukanovite } \mathrm{Fe}_{2}(\mathrm{OH})_{2} \mathrm{CO}_{3}\end{array}$ & Insulating \\
\hline $\begin{array}{l}\text { Presence of magnetite as strips at the } \\
\text { CPL/TM interface without visible } \\
\text { connection to the metal on the cross } \\
\text { section }\end{array}$ & $\begin{array}{l}\text { Ferrous carbonates: insulating } \\
\text { Strips: conductive (up to } 100 \mathrm{nA} \text { ) }\end{array}$ \\
\hline $\begin{array}{c}\text { Presence of magnetite as islets isolated in } \\
\text { the ferrous carbonate matrix }\end{array}$ & $\begin{array}{l}\text { Ferrous carbonates: insulating } \\
\text { Magnetite: less conductive ( } \sim 10 \mathrm{pA}) \text { than } \\
\text { magnetite strips ( } 100 \mathrm{nA}) \text { at the same } \\
\text { conditions as C-AFM experiment. }\end{array}$ \\
\hline $\begin{array}{l}\text { Presence of iron sulfides in the external } \\
\text { part of the CPL composed of ferrous } \\
\text { carbonate without visible connection to } \\
\text { the metal on the cross section }\end{array}$ & $\begin{array}{c}\text { Ferrous carbonates: insulating } \\
\text { Iron sulfides: conductive }(\sim 4 p A) \\
\text { Magnetite strip (visible on the same C-AFM } \\
\text { current image): }(\sim 2 \mathrm{pA})\end{array}$ \\
\hline
\end{tabular}

The corrosion products typical of a deaerated corrosion in a carbonated environment have been highlighted: the CPL is mainly composed of ferrous carbonate phases such as siderite and chukanovite, as previously reported in various studies concerning archaeological artefacts [3-9] or low-carbon steel coupons corroded for a few months in laboratory experiments [4]. These phases are formed following the precipitation of ferrous cations 
formed through the aqueous anodic dissolution of iron metal with the carbonate anions of the medium $[14,28]$.

In a few zones of the $C P L$, minor phases are observed, such as magnetite present in the form of strips at the CPL/TM interface or as islets surrounded by the ferrous carbonate matrix. The presence of magnetite in the periphery of the CPL and in the outer part of the ferrous carbonate matrix could correspond to the first step in the corrosion process of the iron objet [29]. However, magnetite was not only evident in the outer part of the CPL but was also observed in the carbonate matrix, as in the studies by Saheb et al. [30]. In this latter configuration, the formation of magnetite could result from local changes in temperature, $\mathrm{pH}$ and carbonate concentration. As indicated by the Pourbaix diagram that shows the existence of magnetite and ferrous carbonate domains, depending on changes in local conditions, ferrous carbonates or magnetite can be present in the CPL.

Iron sulfides are also observed in the CPL suggesting a possible role of sulfatereducing bacteria, while the growth metabolism is based on the transformation of the sulfate anions of an anoxic medium into sulfide ions. The subsequent formation of iron sulfides is due to the interaction of ferrous ions from the anodic dissolution of iron metal and sulfide ions $[9,31]$. The magnetite strips and islets, as well as iron sulfides present in the ferrous carbonate matrix or at the CPL/TM interface do not present visible connectivity to the iron metal in the cross section.

From the C-AFM measurements, the corrosion patterns containing only ferrous carbonate phases, such as siderite and chukanovite, are non-conductive on a submicrometric scale and according to the minimal current detectable by C-AFM which is 50fA. This is consistent with the fact that this phase is reported to be isolating [20]. Some studies state that, for siderite formed within localized corrosion of carbon steel, this phase can 
demonstrate less resistive behaviour due to the local presence in the measured zone of undissolved components from the steel, namely cementite $\mathrm{Fe}_{3} \mathrm{C}$ [32]. In the present study, these compounds that are reportedly micrometric in size [20] were not observed by either optical microscopy or $\mu$ Raman.

The resistivity values reported for magnetite in the literature are $10^{-2}-10^{-3} \Omega . c m[25,27]$ due to closeness of $\mathrm{Fe}^{2+}$ and $\mathrm{Fe}^{3+}$ on octahedral sites. In our study, regardless of morphology (underneath strips or islets) inside the CPL, the C-AFM measurements reveal an electrical connection with the metallic substrate even far from the $M / C P L$ interface in the outer part of the insulating CPL made of carbonates.

Moreover, weaker electrical conduction is observed for the magnetite islets with the measured current in the tens of $\mathrm{pA}$, compared to hundreds of $\mathrm{pA}$ for the magnetite in strips. This difference in conductivity values could be due to a lower crystallinity of the magnetite islets. Indeed, Sarkar et al. [33], by coupling XRD, TEM and impedance analysis, studied the effect of variable sized magnetite nano-hollow spheres (from 100 to $725 \mathrm{~nm}$ in diameter) on electrical properties and observed that larger spheres are more conductive than smaller ones. Lopez Maldonaldo et al. [34] examined the effect of crystallite size on the conductivity of magnetite nanoparticles of sizes $(30,40$ and $50 \mathrm{~nm})$ by coupling TEM and EIS observations: these authors showed that the resistivity of magnetite increases with a decrease in crystallite size.

Concerning iron sulfides, the resistivity values are reported to be between $10^{-3}$ and $5 \times 10^{-3} \Omega . c m$ [27] suggesting electrical conductivity in these compounds. In our study, the iron sulfides demonstrated conductive behaviour. Although they are embedded in the insulating ferrous carbonate matrix these results show that iron sulfides are connected to the iron metal in the volume of the sample. 
The fact that magnetite and iron sulfides are connected to the metal, despite being located in the outer part of the insulating ferrous carbonate matrix or embedded inside it, raises the question of how this connectivity happens. C-AFM measurements provide twodimensional information and the possible presence of a network made of magnetite and/or iron sulfides in the volume of the $\mathrm{CPL}$, and electrically connected to iron metal, could explain these observations.

These findings have important consequences for the corrosion mechanisms of such systems. The electrons produced by the anodic dissolution of metallic iron could be conducted to different locations in the CPL (islets of magnetite, sulfur-containing phases or strips of magnetite) leading to a decoupling of anodic and cathodic corrosion reactions. Our observations complete those obtained by Saheb et al. $[6,7]$ with a reaction tracing based on the use of the $\mathrm{Cu}^{2+} / \mathrm{Cu}^{0}$ redox couple on the thick ferrous corrosion layer of iron archaeological nails corroded in anoxic carbonated environments. These authors revealed the presence of $\mathrm{Cu}^{0}$ nodules in the whole $\mathrm{CPL}$ suggesting that the electrons are consumed everywhere in the layer. Here we see that, on the one hand, the cathodic reaction could happen anywhere in the layer where magnetite or sulfur is present and connected to the metal, even at distances up to $100 \mu \mathrm{m}$ from the metal/CPL interface. On the other hand, the fact that carbonates are not conductive contradicts the possibility of reducing $\mathrm{Cu}^{2+}$ anywhere in the layer as suggested in $[6,7]$.

Another important consequence of this study is that the transport in the corrosion layer (and especially that of the oxidative species such as $\mathrm{H}_{2} \mathrm{O}$ in the pores of the corrosion products) may not be the only mechanism controlling the kinetics. The number of connected zones in the outer part of the CPL is also a crucial parameter. 


\section{Conclusion}

This study illustrates the value of combining characterization methods such as $\mu R S$, and FEG-SEM and C-AFM to describe, at the sub-micrometric and nanometric scales, the corrosion product layers of iron corroded in carbonated anoxic environments. $\mu$ RS was conducted to determine the crystalline nature of the corrosion products and FESEM to document their distribution. The electrical properties of the corrosion product layers were characterized by C-AFM. The main phase identified in the CPL is composed of ferrous carbonates (siderite, or a mixture of siderite and chukanovite) and is insulating. The conductive character of the CPL is induced by the presence of magnetite or iron sulfides located at the TM/CPL interface or inside the CPL and connected to the metal. This may suggest that the electrons produced by the anodic dissolution of iron metal could be conducted to the external part of the CPL through a nanometric tridimensional network of magnetite strips locally connected to the metal and passing through the ferrous carbonate matrix.

The data concerning the electronic properties of the CPL will be expanded by X-ray tomography experiments to obtain information at the nanometric scale on the porosity network inside the CPL and to identify the distribution of magnetite and iron sulfides in the entire volume of the CPL.

\section{Acknowledgements}

The authors wish to thank Dr Cindy Rountree for her helpful and fruitful discussions during the C-AFM experiments. 


\section{References}

[1] A. Demoz, S. Papavinasam, K. Michaelian, R.W. Revie, Measurement of corrosion potentials of the internal surface of operating high-pressure oil and gas pipelines, Journal of ASTM International 5 (2008) 300-312.

[2] A. Clanfield, F. Cattant, D. Crusset, D. Féron, Corrosion issues in nuclear industry today, Materials Today 11 (2008) 32-37.

[3] D. Neff, P. Dillmann, L. Bellot-Gurlet, G. Beranger, Corrosion of iron archaeological artefacts in soil: characterisation of the corrosion system, Corrosion Science 47 (2005) 515535.

[4] M. Saheb, D. Neff, P. Dillmann, H. Matthiesen, E. Foy, Long-term corrosion behaviour of low-carbon steel in anoxic environment: characterisation of archaeological artefacts, J. Nucl. Mater. 379 (2008) 118-123.

[5] M. Saheb, D. Neff, P. Dillmann, H. Matthiesen, E. Foy and L. Bellot-Gurlet, Multisecular corrosion behaviour of low carbon steel in anoxic soils: Characterisation of corrosion system on archaeological artefacts, Materials and Corrosion 60, No. 2 (2009) 99.

[6] M. Saheb, D. Neff, L. Bellot-Gurlet and P. Dillmann, Raman study of a deuterated iron hydroxycarbonate to assess long-term corrosion mechanisms in anoxic soils, J. Raman Spectrosc. 42 (2011a) 1100-1108.

[7] M. Saheb, D. Neff, C. Bataillon, E. Foy, P. Dillmann, Copper tracing to determine the micrometric electronic properties of a thick ferrous corrosion layer formed in anoxic medium, Corrosion Science 53 (2011b) 2201-2207.

[8] Y. Léon, M. Saheb, E. Drouet, D. Neff, E. Foy, E. Leroy, J.J. Dynes, P. Dillmann, Interfacial layer on archaeological mild steel corroded in carbonated anoxic environments studied with coupled micro and nano probes, Corrosion Science 88 (2014) 23-35.

[9] S. Grousset, M. Bayle, A. Dauzeres, D. Crusset, V. Deydier, Y. Linard, P. Dillmann, F. Mercier-Bion, D. Neff, Study of iron sulphides in long-term iron corrosion processes: characterisations of archaeological artefacts, Corrosion Science 112 (2016) 264-275.

[10] Y. Léon, P. Dillmann, D. Neff, M. Schlegel, E. Foy, J.J. Dynes, Interfacial layers at a nanometre scale on iron corroded in carbonated anoxic environments, RSC Advances 7 (2017) 20101 
[11] C. Bataillon, C. Musy, M. Roy, Corrosion des surconteneurs de déchets, cas d'un surconteneur en acier faiblement allié, J. Phys. IV France (2001) 94-99.

[12] M. Schlegel, C. Bataillon, F. Brucker, C. Blanc, D. Prêt, E. Foy, M. Chorro, Corrosion of metal iron in contact with anoxic clay at $90^{\circ} \mathrm{C}$ : characterization of the corrosion products after two years of interaction, Applied Geochemistry 51 (2014) 1-14.

[13] B. Soerensen, D. Gregory, In-situ preservation of artefacts in Nydam-Mose, Metal 98 Conference on Metals Conservation, Draguignan-Figanières, France, 1998, ed. W. Mourey, L. Robbiola, James \& James, London, 94-99.

[14] H. Matthiesen, L.R. Hilbert, D.J. Gregory, The occurrence and stability of siderite as a corrosion product on archaeological iron from a waterlogged environment, Stud. Conserv. 48 (2003) 183-194.

[15] N. Taniguchi M. Kawasaki, S. Kawakami, M. Kubota, Corrosion behaviour of carbon steel in contact with bentonite under anaerobic condition, in: Prediction of long term corrosion behaviour in nuclear waste systems, in: Proceedings $2^{\text {nd }}$ International Workshop, European Federation of Corrosion and ANDRA, Nice, 2004.

[16] V. Fell, M. Ward, Iron sulphides: corrosion products on artifacts from waterlogged deposits, in: Metal 98 Conference on Metals Conservation, Draguignan-Figanières, France, 1998, ed. W. Mourey, L. Robbiola, James \& James, London.

[17] D. Arribet-Deroin, Fondre le fer en gueuses au XVle siècle. Le haut fourneau de Glinet en pays de Bray (Normandie) in Archéologie, Paris I Sorbonne, Paris, 2001.

[18] N. Platts, D. Blackwood, C.C. Naish, Anaerobic oxidation of carbon steel in granitic groundwaters: a review of relevant literature, in: SKB (Ed.), Technical Report, SKB, Stockolm, Sweden, 1994.

[19] N.R. Smart, D.J. Blackwood, L. Werme, Anaerobic corrosion of carbon steel and cast iron in artificial groundwaters: Part 1 - Electrochemical aspects, Corros. NACE Inter. 58 (2002) 547-559.

[20] J.L. Crolet, N. Thevenot, S. Nesic, Role of conductive corrosion products in the protectiveness of corrosion layers, Corros. NACE inter. 54 (1998) 194-203.

[21] R.M. Cornell, U. Schwertmann, The Iron Oxides: Structure, Properties, Reactions, Occurrences and Uses, Wiley-VCH Verlag, Weinheim, 2003.

[22] N.N. Greenwood, Ionic Crystals Lattice Defects and Nonstoechiometry, Butterworths, London, 1968. 
[23] J.M. Mativetsky, Y.L. Loo, P. Samorı, Elucidating the nanoscale origins of organic electronic function by conductive atomic force microscopy, Journal of Materials Chemistry C, 2 (2014) 3118-3128.

[24] J.A. Bourdoiseau, M. Jeannin, C. Rémazeilles, R. Sabot and P. Refait, The transformation of mackinawite into greigite studied by Raman spectroscopy, Journal of Raman Spectroscopy, 42 (2011) 496-504.

[25] N.M. Botrous El Radramany, E.F. Mina, H.D. Merchant, S. Arafa, Electrical Resistivity of magnetite and nickel ferrous ferrite above $300^{\circ} \mathrm{K}$, Journal of the American Ceramic Society, 62 No. 3-4 (1979) 113-116.

[26] I.C. Pearce, R.A.D. Pattrick, D.J. Vaughan, Electrical and magnetic properties of sulfides, Reviews in Mineralogy and Geochemistry, 61 (2006) 127-180.

[27] L. Blaney, Magnetite (Fe304): Properties, Synthesis, and Applications, Lehigh Review, 15 (2007).

[28] C. Rémazeilles, P. Refait, Fe(II) hydroxycarbonate $\mathrm{Fe}_{2}(\mathrm{OH})_{2} \mathrm{CO}_{3}$ (chukanovite) as iron corrosion product: Synthesis and study by Fourier Transform Infrared Spectroscopy, Polyhedron 28 Issue 4 (2009) 749-756.

[29] R. Bertholon, La limite de la surface d'origine des objets métalliques archéologiques, Caractérisation, localisation et approche des mécanismes de conservation, in Archéologie Paris I, Paris, 2000.

[30] M. Saheb, M. Descostes, D. Neff, H. Matthiesen, A. Michelin, P. Dillmann, Iron corrosion in anoxic soil: comparison between thermodynamic modelling and ferrous archaeological artefacts characterised along with the local in situ geochemical conditions, Applied Geochemistry 25 (2010) 1937-1948.

[31] C. Rémazeilles, M. Saheb, D. Neff, E. Guilminot, K. Tran, J.A. Bourdoiseau, R. Sabot, M. Jeannin, H. Matthiesen, P. Dillmann, P. Refait, Microbiologically influenced corrosion of archeological artefacts: characterisation of iron(II) sulfides by Raman spectroscopy, Journal of Raman Spectroscopy 41 (2010) 1425.

[32] G. Schmitt, M. Mueller, M. Papenfuss, Understanding localized CO2 corrosion of carbon steel from physical properties of iron carbonate scales, Corros. 99 NACE Inter., Houston, (1999) Paper 38.

[33] D. Sarkar, M. Mandal, K. Mandal, Domain controlled magnetic and electric properties of variable sized magnetite nano-hollow spheres, Journal of Applied Physics 112 (2012) 064318. 
[34] K.L. Lopez Maldonado, P. de la Presa, M.A. de la Rubia, P. Crespo, J. de Frutos, A. Hernando, J.A. Matutes Aquino, J.T. Elizalde Galindo, Effects of grain boundary width and crystallite size on conductivity and magnetic properties of magnetite nanoparticles, J. Nanopart. Res., 16 (2014) 2482. 